\title{
Article \\ Active Components from Cassia abbreviata Prevent HIV-1 Entry by Distinct Mechanisms of Action
}

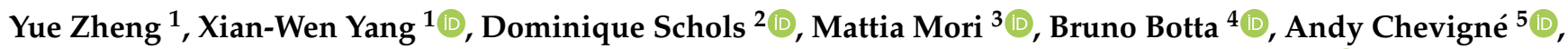 \\ Martin Mulinge ${ }^{5,6}$, André Steinmetz ${ }^{1}$, Jean-Claude Schmit ${ }^{5,7}$ and Carole Seguin-Devaux ${ }^{5, * \mathbb{C}}$
}

1 Laboratory of Cellular and Molecular Oncology, Luxembourg Institute of Health, L-1445 Luxembourg, Luxembourg; yue.zheng@path.utah.edu (Y.Z.); yangxianwen@tio.org.cn (X.-W.Y.); andre.steinmetz@lih.lu (A.S.)

2 Laboratory of Virology and Chemotherapy, Department of Microbiology, Immunology and Transplantation, Rega Institute for Medical Research, KU Leuven, 3000 Leuven, Belgium; dominique.schols@kuleuven.be

3 Department of Biotechnology, Chemistry and Pharmacy, University of Siena, 53100 Siena, Italy; mattia.mori@unisi.it

4 Department of Chemistry and Technology of Drugs, Sapienza University of Rome, 00185 Rome, Italy; bruno.botta@uniroma1.it

5 Department of Infection and Immunity, Luxembourg Institute of Health, L-4354 Esch-sur-Alzette, Luxembourg; andy.chevigne@lih.lu (A.C.); mmulinge@uonbi.ac.ke (M.M.); Jean-Claude.Schmit@ms.etat.lu (J.-C.S.)

6 Department of Biochemistry, School of Medicine, University of Nairobi, Nairobi, Kenya

7 Service National of Infectious Diseases, Centre Hospitalier de Luxembourg, L-1210 Luxembourg, Luxembourg

updates

Citation: Zheng, Y.; Yang, X.-W. Schols, D.; Mori, M.; Botta, B.;

Chevigné, A.; Mulinge, M.; Steinmetz, A.; Schmit, J.-C.; Seguin-Devaux, C. Active Components from Cassia abbreviata Prevent HIV-1 Entry by Distinct Mechanisms of Action. Int. J. Mol. Sci. 2021, 22, 5052.

https: / / doi.org/10.3390/ ijms22095052

Academic Editors: Se-Kwon Kim

Received: 18 February 2021

Accepted: 4 May 2021

Published: 10 May 2021

Publisher's Note: MDPI stays neutral with regard to jurisdictional claims in published maps and institutional affiliations.

Copyright: (c) 2021 by the authors Licensee MDPI, Basel, Switzerland. This article is an open access article distributed under the terms and conditions of the Creative Commons Attribution (CC BY) license (https:// creativecommons.org/licenses/by/ $4.0 /)$.
* Correspondence: carole.devaux@lih.lu

\begin{abstract}
Cassia abbreviata is widely used in Sub-Saharan Africa for treating many diseases, including HIV-1 infection. We have recently described the chemical structures of 28 compounds isolated from an alcoholic crude extract of barks and roots of C. abbreviata, and showed that six bioactive compounds inhibit HIV-1 infection. In the present study, we demonstrate that the six compounds block HIV-1 entry into cells: oleanolic acid, palmitic acid, taxifolin, piceatannol, guibourtinidol$(4 \alpha \rightarrow 8)$-epiafzelechin, and a novel compound named as cassiabrevone. We report, for the first time, that guibourtinidol-( $4 \alpha \rightarrow 8)$-epiafzelechin and cassiabrevone inhibit HIV-1 entry (IC 50 of 42.47 $\mu \mathrm{M}$ and $30.96 \mu \mathrm{M}$, respectively), as well as that piceatannol interacts with cellular membranes. Piceatannol inhibits HIV-1 infection in a dual-chamber assay mimicking the female genital tract, as well as HSV infection, emphasizing its potential as a microbicide. Structure-activity relationships (SAR) showed that pharmacophoric groups of piceatannol are strictly required to inhibit HIV-1 entry. By a ligand-based in silico study, we speculated that piceatannol and norartocarpetin may have a very similar mechanism of action and efficacy because of the highly comparable pharmacophoric and 3D space, while guibourtinidol- $(4 \alpha \rightarrow 8)$-epiafzelechin and cassiabrevone may display a different mechanism. We finally show that cassiabrevone plays a major role of the crude extract of $C A$ by blocking the binding activity of HIV-1 gp120 and CD4.
\end{abstract}

Keywords: natural products; Cassia abbreviata; HIV-1 entry; piceatannol; structure-activity relationship; pharmacophoric studies; norartocarpetin

\section{Introduction}

Human Immunodeficiency Virus (HIV) infection was affecting about 38 million people (http: / / www.unaids.org/ accessed on 18 February 2021) around the world in 2019. The vast majority of HIV-infected patients live in low- and middle-income countries, particularly in Sub-Saharan Africa. Combined antiretroviral therapy (cART) has largely improved the life of HIV-infected patients [1], and is the leading factor in reducing the number of new HIV-infected cases worldwide. Current cART is, nevertheless, facing many challenges for 
life-long adherence [2]; treatment-experienced patients encountered viral mutants resistant to multiple drugs, and women are more prone to HIV infection than men in Sub-Saharan Africa [3]. The development of new anti-HIV drugs and potent microbicides is, therefore, highly required.

Around 30 antiretroviral drugs have been released for clinical practice, inhibiting HIV-1 at different stages of the viral life cycle [4]. Novel therapeutic strategies could take advantage of the multiple events involved in the entry process [5]. HIV-1 attaches to the cell membrane, engaging its surface envelope glycoprotein gp120 to bind subsequently the CD4 receptor and either to the $\mathrm{C}-\mathrm{X}-\mathrm{C}$ chemokine receptor type 4 (CXCR4) or C-C chemokine receptor type 5 (CCR5) co-receptor, and further triggering conformational changes in HIV-1 envelope glycoproteins leading to the membrane fusion process [6]. New compounds targeting interactions with cellular proteins/membranes or viral membranes might be less prone to selecting for drug resistance, should reduce the formation of viral reservoirs, and could additionally display broad spectrum antiviral effects than compounds targeting viral replication [7].

In the past decades, a high number of drugs have been developed from natural products and showed their critical power in medical therapies, such as the anti-malarial drug artemisinin and the anticancer drug paclitaxel [8]. The 2015 half Nobel Prize award for artemisinin's discovery recently emphasized the enormous value of traditional medicine and ethnopharmacology. In this regard, Cassia abbreviata (C. abbreviata) is a tropical tree in Cassia genus, Fabaceae family, which is indigenous to South-East Africa, widespread in African countries and commonly used in the African local medicines [9]. Roots, barks, and leaves are taken as decoction or chewed, for healing abdominal pain, fever, cough, snake bite, malaria, infections, and, in particular, HIV-1 infection [10,11]. We have recently reported the isolation of 28 compounds from a crude extract of bark and roots of $C$. abbreviata [12]. Six bioactive compounds showed anti-HIV activity. Leteane et al. [13] has previously reported that a tanning free crude extract of $C$. abbreviata root inhibited HIV-1c (MJ4) replication in human peripheral blood mononuclear cells (PBMCs). It is known that a variety of compounds, including alkaloids, tannins, anthraquinones, and flavonoids, may contribute to the biological effect of plant medicines [10], while the active components of $C$. abbreviata's, as well as their mode of action, are still unknown.

To better understand the mode of action of the traditional medicine plant $C$. abbreviate, we elucidated the antiviral activity of $C$. abbreviata's crude extract (pulverized from barks and roots and extracted with 95\% ethanol) against several HIV-1 strains, and demonstrated that six compounds isolated from C. abbreviata were inhibiting HIV-1 entry, including a novel compound cassiabrevone. We showed here the different mode of action of the active compounds in both structure studies and biological tests. Cassiabrevone plays a major role in the CE of C. abbreviata by inhibiting the binding activity of gp120 and CD4. Piceatannol blocks HIV-1 entry using a different mechanism by targeting cell and viral membrane. Optimized synthetic derivatives from cassiabrevone and piceatannol could be used as a microbicide.

\section{Results}

\subsection{The Crude Extract and Purified Compounds of C. abbreviata Inhibit HIV-1 Entry}

The anti-HIV-1 activity of C. abbreviata was first assessed on MT4 cells and human peripheral blood mononuclear cells (PBMCs) from healthy donors using the HIV-1 reference strain IIIB (X4 tropic virus) and ADA-M (R5 tropic virus), as well as 2 non-B HIV-1 primary clinical isolates carrying several drug resistance mutations to nucleoside/nucleotide reverse transcriptase inhibitor (NRTI), to non-nucleoside reverse transcriptase inhibitor (NNRTI), and to protease inhibitors (PI). The crude extract (CE) inhibited HIV-1 infection in MT4 cells infected with the reference strain HIV-1-IIIB (X4 virus, IC50 $=21.75 \pm 1.20 \mu \mathrm{g} / \mathrm{mL})$ at non-toxic concentrations (CC50 above $1000 \mu \mathrm{g} / \mathrm{mL}$ ). As shown in Figure 1A, CE inhibited HIV-1 infection in PBMCs with $\mathrm{IC}_{50}$ ranging from 10.47 to $40.77 \mu \mathrm{g} / \mathrm{mL}$. The NNRTI efavirenz (EFV), the NRTI azidothymidine (AZT), and the fusion inhibitor enfuvirtide (T20) 
were used as positive controls. As expected, EFV and AZT did not inhibit viral infection of the respective clinical isolates which carried resistance mutations to NRTI and NNRTI, while T20 inhibited both HIV-1 reference strains and clinical isolates. We also examined the cytotoxicity of $C E$ in PBMCs and found that $C E$ was not toxic after 2 days treatment (Figure 1B). To further determine whether $C E$ induces cell apoptosis, we measured the apoptotic cells by Annexin-V/PI staining after incubating CE and PBMCs for $48 \mathrm{~h}$. As shown in Figure $1 \mathrm{C}, 30 \mu \mathrm{M} \mathrm{H}_{2} \mathrm{O}_{2}$, used as a positive control, induced $20 \%$ apoptosis, while $\mathrm{CE}$ did not induce any apoptosis as in non-treated cells. These data indicate that $\mathrm{CE}$ has an anti-HIV-1 activity without inducing any cytotoxicity or apoptosis.

A.


\begin{tabular}{|c|c|c|c|c|}
\hline & \multicolumn{4}{|c|}{$\mathrm{IC}_{50}$} \\
\hline & Clinical isolate \#1 & Clinical isolate \#2 & IIIB & ADA-M \\
\hline $\mathrm{CE}(\mu \mathrm{g} / \mathrm{mL})$ & 23.06 & 10.47 & 40.77 & 13.53 \\
\hline $\mathrm{EFV}(\mathrm{nM})$ & $>10$ & $>10$ & 0.10 & 0.17 \\
\hline $\mathrm{AZT}(\mathrm{nM})$ & 6.70 & $>1000$ & 7.07 & 7.31 \\
\hline $\mathrm{T} 20(\mathrm{nM})$ & 8.25 & 1.93 & 0.64 & 0.67 \\
\hline
\end{tabular}

Figure 1. Cont. 

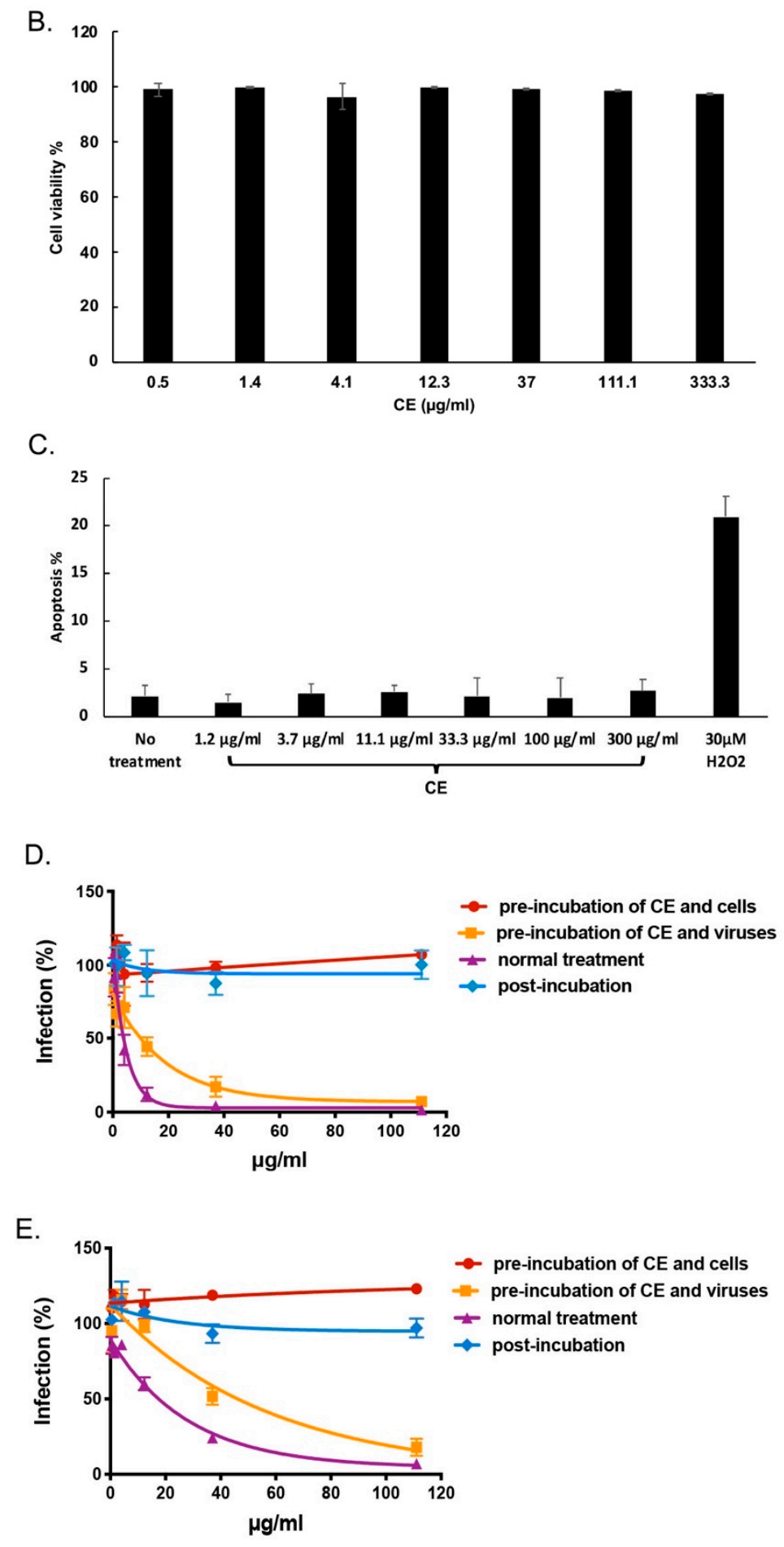

Figure 1. Crude extract (CE) of C. abbreviata inhibits HIV-1 entry into cells. (A) PBMCs isolated from healthy donor were treated with CE, or the NNRTI inhibitor efavirenz (EFV), the NRTI inhibitor azidothymidine (AZT) or the fusion inhibitor enfuvirtide (T20) for 7 days during infection. HIV-1 infection was assessed by measuring P24 in cell supernatants via ELISA. (B) PBMCs were treated with CE for 2 days. Cell viability was measured by flow cytometry. (C) PBMCs treated with CE were stained with Annexin-V/PI and measured by flow cytometry. Apoptosis level was calculated by counting both early apoptotic cells (Annexin-V+) and late apoptotic cells (PI+) (D,E). CE was tested in a multi-dosing time assay (D) using U373CD4-CXCR4 cells against pseudotype virus pNL4.3AEnvLuc-HXB2 and (E) using U373-CD4-CCR5 cells against pseudotype virus pNL4.3AEnvLuc-BAL. CE was either pre-incubated with cells or viruses for $2 \mathrm{~h}$, or incubated with cells and viruses during the $2 \mathrm{~h}$ spinoculation infection (normal treatment), or added to the cells after infection (post-incubation). HIV-1 infection was assessed by measuring luciferase in the cell supernatant. Three independent experiments were performed in triplicates. 
To further characterize at which step of infection CE inhibited HIV-1, multi-dosing time assay experiments were performed with U373-CD4-CXCR4/CCR5 cells against infection of pseudotyped virus pNL4.3 $\triangle E n v$ Luc-HXB2 and pNL4.3 $\triangle E n v$ Luc-BAL.Pseudotyped viruses pNL4.3 $\triangle E n v$ Luc-HXB2/BAL are only able for one cycle of viral infection and allow us to assess the infection level by measuring the luciferase value in the cell supernatant. As shown in Figure 1D,E, the inhibitory effect of CE was apparent when CE was preincubated with the virus for $2 \mathrm{~h}$ cells $\left(\mathrm{IC}_{50} \mathrm{HXB} 2=2.57 \mu \mathrm{g} / \mathrm{mL}, \mathrm{IC}_{50} \mathrm{BAL}=11.41 \mu \mathrm{g} / \mathrm{mL}\right)$ but not with the cells, as well as when $\mathrm{CE}$ was incubated with both cells and viruses during $2 \mathrm{~h}$ spinoculation infection (normal treatment) $\left(\mathrm{IC}_{50} \mathrm{HXB} 2=13.37 \mu \mathrm{g} / \mathrm{mL}, \mathrm{IC}_{50}\right.$ $\mathrm{BAL}=67.40 \mu \mathrm{g} / \mathrm{mL}$ ) but not after infection (CE was added during the first $2 \mathrm{~h}$ after the spinoculation). These results indicate that CE inhibits HIV-1 infection at an early stage of the HIV-1 infection independently of co-receptor usage

Since we identified 6 compounds with an anti-HIV-1 activity [12], the anti-HIV activities of isolated compounds from C. abbreviata were further assessed against pseudotype viruses pNL4.3 $\triangle E n v L u c-H X B 2$ when the compounds were added only at the time of infection to identify the compounds targeting HIV-1 entry. Four known anti-HIV compounds were characterized: oleanolic acid, palmitic acid, taxifolin, and piceatannol (Figure 2A). In our experiment, oleanolic acid, palmitic acid, taxifolin and piceatannol inhibited HIV-1 entry at non-cytotoxic concentration showing $\mathrm{IC}_{50}$ at $34.87 \pm 9.09 \mu \mathrm{M}, 87.48 \pm 16.12 \mu \mathrm{M}$, $240 \pm 3 \mu \mathrm{M}$, and $10.28 \pm 5.74 \mu \mathrm{M}$, respectively (Figure 2B). Moreover, we identified two other flavonoids that prevent HIV-1 entry: guibourtinidol- $(4 \alpha \rightarrow 8)$-epiafzelechin (IC 50 $42.47 \pm 3.88 \mu \mathrm{M})$ and a novel compound we named as cassiabrevone ( $\left.\mathrm{IC}_{50} 30.96 \pm 5.02 \mu \mathrm{M}\right)$. We will elucidate their mode of action in the last part of this work. We first focused our study on piceatannol since it was never described as an HIV-1 entry inhibitor.

\subsection{Piceatannol Interacts with Both Cell and Viral Membranes and has a Synergistic Effect with HIV-1 Entry Inhibitors}

We first confirmed that piceatannol protected PBMCs against HIV-1 IIIB and HIV-1 ADA-M $\left(\mathrm{IC}_{50}=24.22 \pm 7.13 \mu \mathrm{M}\right.$ and $\mathrm{IC}_{50}=19.91 \pm 0.22 \mu \mathrm{M}$, respectively $)$, and against two non-B HIV-1 primary clinical isolates harboring multi-drug resistance to NRTI, NNRTI, and $\mathrm{PI}\left(\mathrm{IC}_{50}\right.$ of $37.72 \pm 12.54$ and $\left.8.04 \pm 3.07 \mu \mathrm{M}\right)$ (Figure $3 \mathrm{~A}$ ). We also examined the cytotoxicity and apoptosis in the PBMCs treated with piceatannol for 2 days by flow cytometry. As shown in Figure 3B,C, piceatannol was not cytotoxic and did not induce any apoptosis. We next deciphered whether piceatannol targets cells or viruses using the multi-dosing time assay (Figure 3D). In contrast to CE, piceatannol inhibited HIV-1 infection at high concentration when it was pre-incubated with cells but not pre-incubated with the virus, indicating that piceatannol's action is maximal when added together on both surface of cells and viruses. We did not find any effect of piceatannol when added after the step of infection in our pseudotyped assay although the integrase inhibitor raltegravir inhibited HIV-1 infection when added only after the time of infection. 
<smiles>CC1(C)CCC2(C(=O)O)CC[C@]3(C)C(=CC[C@@H]4[C@@]5(C)CC[C@H](O)C(C)(C)[C@@H]5CC[C@]43C)[C@]2(C)C1</smiles>

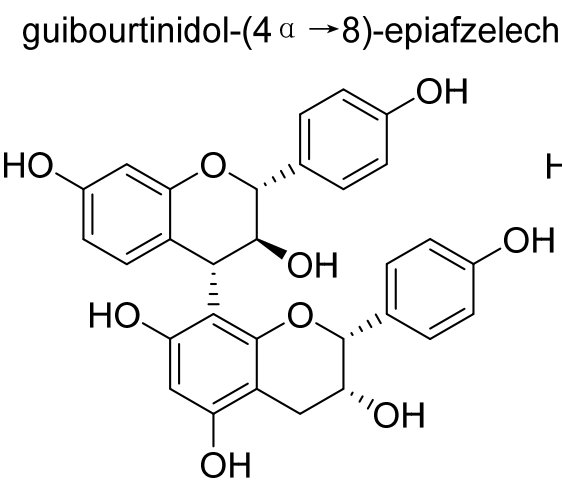<smiles>CCCCCCCCCCCCCCCC(=O)O</smiles>

(A)

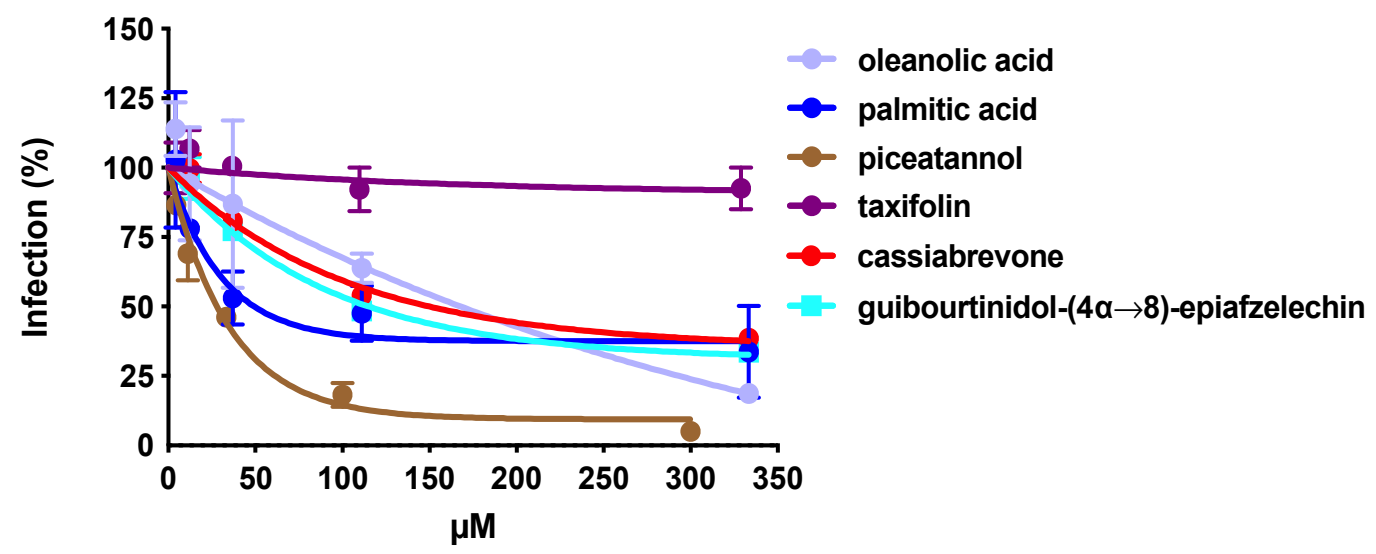

(B)

Figure 2. Anti-HIV-1 entry activity of oleanolic acid, palmitic acid, piceatannol, taxifolin, $4^{\prime} 7$-dihydroxyflavan- $(4,6)-3,4^{\prime}$, 5,7-tetrahydroxyflavan and cassiabrevone. (A) Chemical structures of the compounds. (B) Oleanolic acid, palmitic acid, piceatannol, taxifolin, guibourtinidol- $(4 \alpha \rightarrow 8)$-epiafzelechin, and cassiabrevone were tested on U373-CD4-CXCR4 cells infected with pseudotype virus pNL4.3AEnvLuc-HXB2 when added only at the time of infection. Percentage of infection versus the control cells infected without any compounds is represented. 
A.

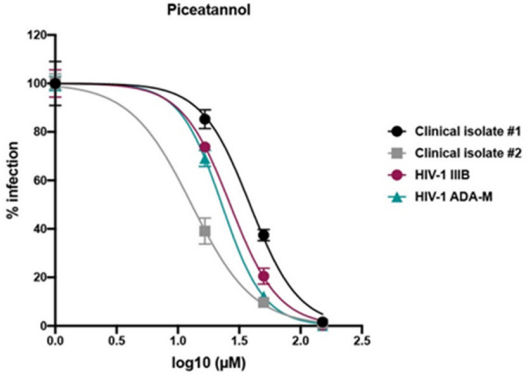

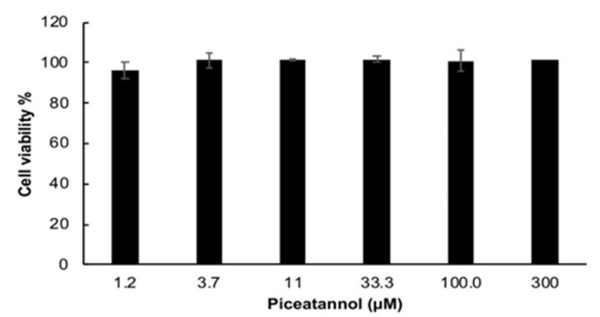

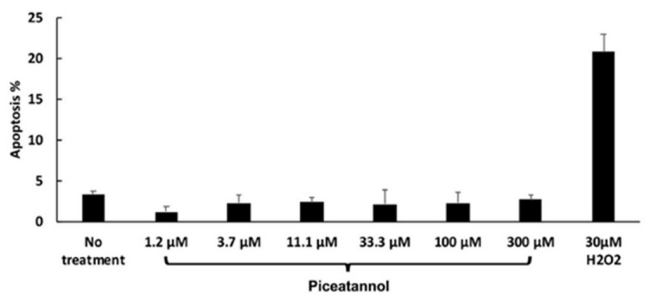

D.

a.

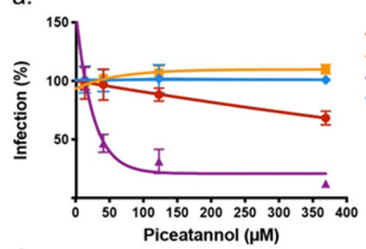

c.

b.

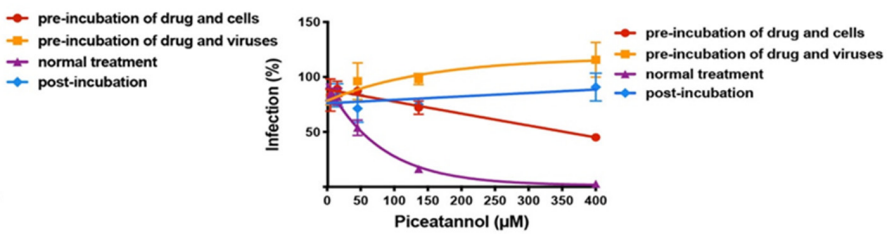

$\rightarrow$ pre-incubation of drug and cells

- normal treatment

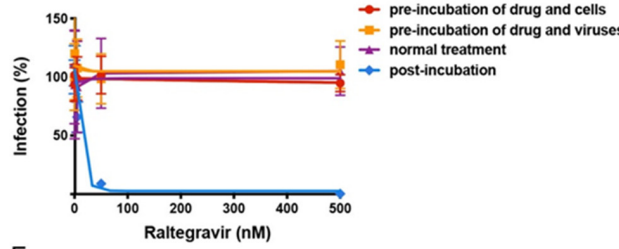

E.
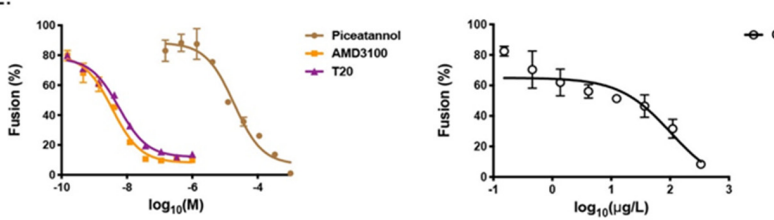

F.
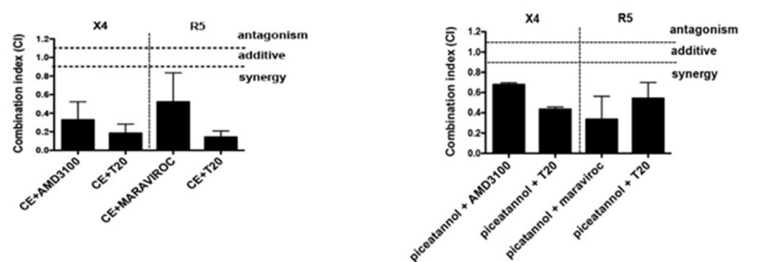

Figure 3. Piceatannol inhibits HIV-1 entry into cells. (A) PBMCs isolated from healthy donor were incubated with piceatannol during infection of HIV-1 reference strains and clinical isolates for 7 days. HIV-1 infection level was assessed by measuring P24 in cell supernatants via ELISA. (B) PBMCs were treated with piceatannol for 2 days. Cell viability was measured by flow cytometry. (C) PBMCs treated with piceatannol were stained with Annexin-V/PI and measured by flow cytometry. Apoptosis level was calculated by counting both early apoptotic cells (Annexin-V+) and late apoptotic cells (PI+). (D) Multi-dosing time assay with piceatannol was performed (a) using U373-CD4-CXCR4 cells against pseudotype virus pNL4.3 $\triangle E n v L u c-H X B 2$ and (b) using U373-CD4-CCR5 cells against pseudotype virus pNL4.3AEnvLuc-BAL. (c) Raltegravir was tested in the multi-dosing time assay using U373-CD4-CXCR4 cells against pseudotype virus pNL4.3 $\triangle E n v L u c-H X B 2$. Percentage of infection relative to no drug treatment is represented. (E) Hela-ENV-Lai cells pretreated with piceatannol, CE, T20, or AMD3100 for $2 \mathrm{~h}$ were incubated with Hela-P4-CXCR4-LTRLacZ cells. HIV-1 fusion level was assessed by measuring $\beta$-Galactosidase activity. (F) Drug combination of CE or piceatannol and AMD3100/maraviroc/T20 was tested in U373-CD4-CXCR4/U373-CD4-CCR5 cells against pseudotype particles pNL4.3AEnvLuc-HXB2/BAL. Combination Index (CI) at 95\% maximal effective concentration (EC95) level was calculated using CompuSyn (ComboSyn, Paramus, NJ, USA). 
To determine if CE and piceatannol block the HIV-1 fusion step, we treated Hela-ENVLai cells with CE, piceatannol, the CXCR4 inhibitor AMD100 or the fusion inhibitor T20 for $2 \mathrm{~h}$ and then co-cultured with Hela-P4-CXCR4LTRLacZ cells for 2 days. We can assess the effect of $\mathrm{CE}$ and piceatannol on the fusion process by measuring the $\beta$-galactosidase activity when the fusion step occurs between Hela-P4-CXCR4 cell and Hela-ENV-Lai cell. As shown in Figure 3E, both CE and piceatannol inhibit HIV-1 fusion efficiently with an $\mathrm{IC}_{50}$ of $22 \mu \mathrm{M}$ and $33.35 \mu \mathrm{g} / \mathrm{mL}$, respectively.

To further investigate if $\mathrm{CE}$ and piceatannol have a synergistic effect with known inhibitors of the fusion step, including the fusion inhibitor T20, the CXCR4 inhibitor AMD3100, or the CCR5 inhibitor Maraviroc, we treated U373-CD4-CXCR4/U373-CD4CCR5 cells with single drug or combined drugs during the infection of pseudotyped viruses pNL4.3AEnvLuc-HXB2/pNL4.3AEnvLuc-BAL for $2 \mathrm{~h}$. By calculating the combination index (CI) using the qualitative Chou and Talalay's method [14], both CE and piceatannol showed synergistic effect with the three known inhibitors T20, AMD100 and Maraviroc $(\mathrm{CI}<0.9)$, which indicates that $\mathrm{CE}$ and piceatannol employ a different mechanism to prevent HIV-1 entry than the fusion inhibitor T20 or the CXCR4/CCR5 inhibitors.

\subsection{CE of C. abbreviata Affects gp120/CD4 Binding Whereas Piceatannol Interacts with Cellular Membranes}

To further examine whether CE and piceatannol affects the binding activity of HIV1 gp120 on the host CD4 receptor, we performed an ELISA assay to analyze if CE or piceatannol could compete with gp120 to bind CD4. As shown in Figure 4A, CE blocked the binding between CD4 and gp120 in a dose-dependent manner, while piceatannol did not. We then further tested if $\mathrm{CE}$ and piceatannol inhibited CD4-gp120 binding by targeting CD4. The binding activity of two anti-CD4 monoclonal antibodies targeting the CD4 domain 1 and 3, in the presence or absence of $C E$ and piceatannol was assessed. As shown in Figure 4B, the positive control soluble CD4 (sCD4) inhibited the two anti-CD4 antibodies binding to CD4, while neither CE nor piceatannol did. Thus, CE inhibits CD4-gp120 binding by targeting gp120.

We observed in Figures 1 and 3 that $\mathrm{CE}$ and piceatannol inhibited viral infection of both $\mathrm{X} 4$ and $\mathrm{R} 5$ viruses, suggesting no specific effect of $\mathrm{CE}$ or piceatannol on the co-receptors CXCR4 and CCR5. We next measured CXCR4/CCR5 binding with their respective chemokine in the presence or absence of $\mathrm{CE}$ and piceatannol. As shown in Figure 4C, the chemokines CXCL12 (C-X-C motif chemokine ligand 12) and CCL5 (C-C motif chemokine ligand 5) inhibited CXCR4/CCR5 binding, respectively, while neither $\mathrm{CE}$ nor piceatannol did.

In line with this evidence, piceatannol, but not $\mathrm{CE}$, inhibited the infection of pseudotype particles of vesicular stomatitis virus (VSV) G proteins $\left(\mathrm{IC}_{50}=79.23 \pm 17.20 \mu \mathrm{M}\right.$, Table 1), indicating that piceatannol inhibits HIV-1 entry independently of any receptors. To determine if $\mathrm{CE}$ or piceatannol had a broad-spectrum antiviral activity or was specific to HIV-1, we tested both on diverse viruses. CE and piceatannol demonstrated anti-viral activity on simplex virus infection HSV-1 and HSV-2 $\left(\mathrm{IC}_{50}\right.$ around $\left.45.0 \mu \mathrm{M}\right)$ but not on influenza, para-influenza, HCV, coxsackie virus, RSV, reovirus, sindbisvirus, punta toro virus, yellow river virus, feline corona virus, and feline herpes virus (Table 1). 
A.

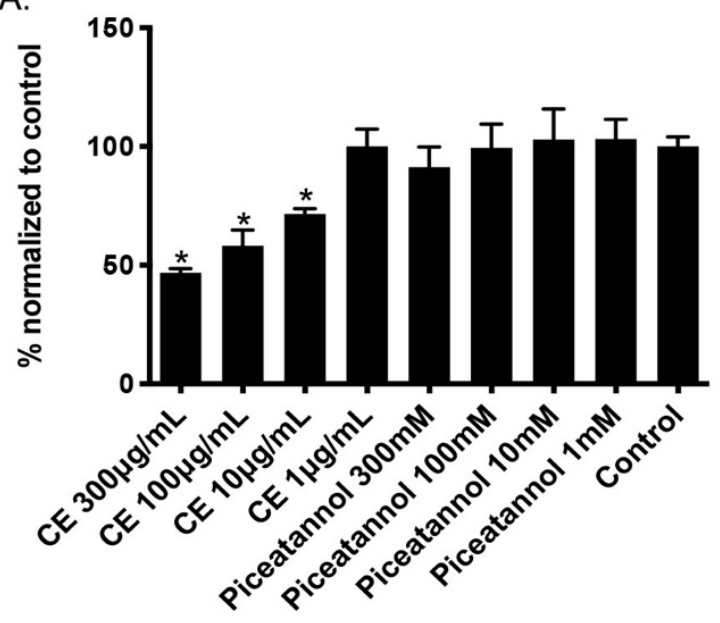

C.

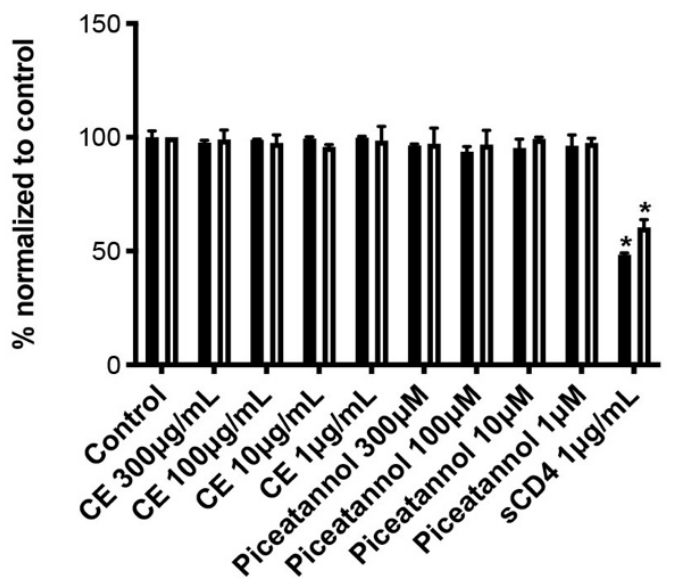

B.

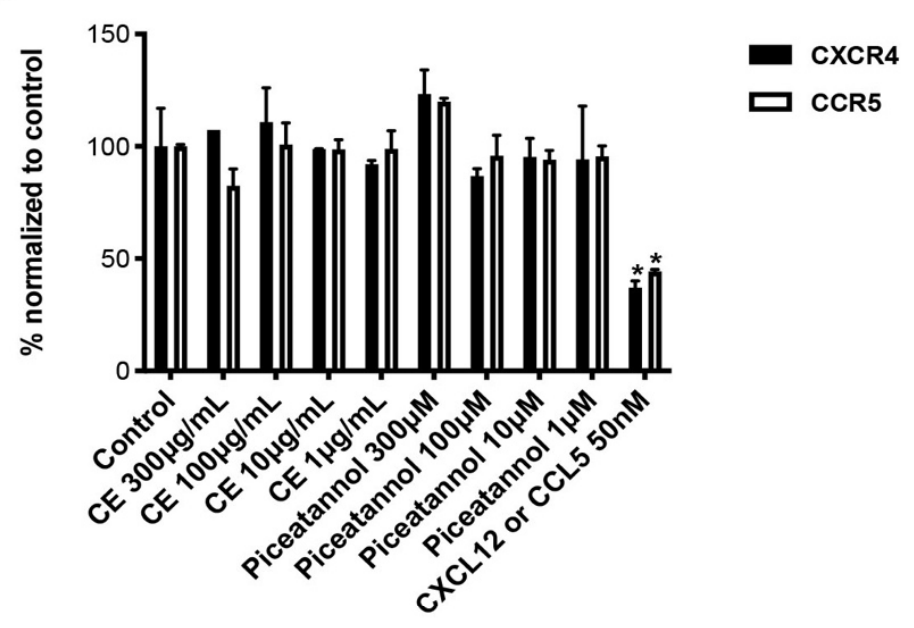

anti-CD4 mAb OKT4

$\square$ anti-CD4 mAb RPA-T4

Figure 4. Binding activity of C. abbreviata's crude extract and piceatannol. (A). CE and piceatannol were tested in an in-house ELISA assay against gp120 binding activity. Data were normalized to control cells without CE/piceatannol treatment. (B) U373-CD4-CXCR4/CCR5 cells were incubated with either anti-CD4 antibody OKT4 or RPA-T4 in the presence of $\mathrm{CE}$ and piceatannol. Soluble CD4 (sCD4) was used as a positive control for binding anti-CD4 antibodies. (C) U373-CD4-CXCR4/CCR5 cells were incubated with either anti-CXCR4 antibody 12G5 or anti-CCR5 antibody 2D7 in the presence of CE and piceatannol. The chemokines CXCL12 and CCL5 were used as positive controls for binding CXCR4 and CCR5, respectively. Data were normalized to the MFI of the control cells. Three independent assays were performed for each binding assay, and ANOVA analysis was done for statistical significance. ${ }^{*} p<0.05$. 
Table 1. Evaluation of CE and piceatannol's activity against various viruses.

\begin{tabular}{cccc}
\hline Cells & Viruses & CE $(\mu \mathrm{g} / \mathbf{m L})$ & Piceatannol $(\mu \mathbf{M})$ \\
\hline HEL & Herpes simplex virus-1 (KOS) & $46.7 \pm 2.9$ & $47.5 \pm 3.5$ \\
HEL & Herpes simplex virus-2 (G) & $39.5 \pm 5.5$ & $45.0 \pm 1.8$ \\
HEL & Herpes simplex virus-1 TK KOS ACV & $45.0 \pm 2.6$ & $45.4 \pm 4.0$ \\
U87 & Vesicular stomatitis virus & $>100$ & $79.2 \pm 17$ \\
MDCK & Influenza A/H1N1 A/Ned/378/05 & $>100$ & $>100$ \\
MDCK & Influenza A/H3N2 A/HK/7/87 & $>100$ & $>100$ \\
MDCK & Influenza B B/Ned/537/05 & $>100$ & $>100$ \\
Huh 7-D & Hepatitis C virus (Jc1) & $>100$ & $>100$ \\
HeLa & Coxsackie virus B4 & $>100$ & $>100$ \\
vero & Coxsackie virus B4 & $>100$ & $>100$ \\
HeLa & Respiratory syncytial virus & $>100$ & $>100$ \\
vero & Para-influenza-3 virus & $>100$ & $>100$ \\
vero & Reovirus-1 & $>100$ & $>100$ \\
vero & sindbisvirus & $>100$ & $>100$ \\
vero & Punta toro virus & $>100$ & $>100$ \\
vero & Yellow fever virus & $>100$ & $>100$ \\
CRFK & Feline corona virus (FIPV) & $>100$ & $>100$ \\
CRFK & Feline herpes virus & $>100$ & $>100$ \\
HEL & Human corona virus &
\end{tabular}

$\mathrm{IC}_{50}$ (inhibitory concentration of viral replication by $50 \%$ ), CE, crude extract of C. abbreviata.

\subsection{Microbicide Activity of Piceatannol}

Since both CE and piceatannol were active against HIV-1, HSV-1, and HSV-2, we further checked its potential as a microbicide. We next tested piceatannol in a dual-chamber system mimicking the epithelium female genital tract (Figure 5A). Both CE and piceatannol inhibited HIV-1 infection of TZM-Bl cells without affecting the confluence layer's TEER and epithelial cells viability. At their $\mathrm{IC}_{50}$ concentration, $\mathrm{CE}$ decreased by more than 4 times HIV-1 infection (from 100 to $18.41 \%$ ), while piceatannol diminished it by 33\% (from 100 to $66.9 \%$ ). For potential microbicide application, anti-HIV compounds should not stimulate target cells. PHA increased the expression of CD25 (early activation marker) and CD69 (late activation marker), whereas $C E$ and piceatannol did not have any effect (Figure 5B). Finally, CE and piceatannol did not prevent transmission of DC-SIGN (Dendritic Cell-Specific Intercellular adhesion molecule-3-Grabbing Non-integrin)-captured virus to $\mathrm{CD} 4^{+} \mathrm{T}$ cells in vitro (data not shown).

\subsection{Structure-Activity Relationship of Piceatannol}

Piceatannol emerged from this study as a promising anti-HIV-1 compounds extracted from C. abbreviata. Since molecular details of piceatannol interaction with its target(s) are currently not available, we performed a structure-activity relationship (SAR) study with the aim to understand the chemical and pharmacophoric features of piceatannol that are relevant for its anti-HIV activity. Seventeen chemical analogues of piceatannol (molecules 1-17, Figure 6) were designed and retrieved from commercial vendors and from an inhouse library of natural products and their derivatives [15-19] and tested in vitro against HIV-1 entry and HIV-1 infection using the pseudotype and the MTT assay, respectively. Compounds 1-13 are stilbene derivatives endowed with subtle chemical modifications with respect to piceatannol (i.e., molecules $\mathbf{4}$ and 5 ) or bearing larger substituents (i.e., 6-11 and longistilines 12 and 13) showing no anti-HIV activity. Besides, the two flavones hispidulin 14 and norartocarpetin 15, and the two styrene derivatives 16 and methyl ferulate 17 were tested. Only compounds that do not bear the stilbene scaffold showed some activity: methyl ferulate 17 at high concentrations $\left(\mathrm{IC}_{50}=600 \pm 22 \mu \mathrm{M}\right)$ and norartocarpetin 15 $\left(\mathrm{IC}_{50}=39 \pm 5 \mu \mathrm{M}, \mathrm{CC}_{50}>500 \mu \mathrm{M}\right)$, the latest showing antiretroviral activity similar to piceatannol. Norartocarpetin is structurally related to taxifolin, although it is noticeably more potent. This result clearly indicates that pharmacophoric features of piceatannol are highly specific, and that subtle modifications to its chemical structure determine 
a significant drop of anti-HIV-1 activity. Accordingly, it is not surprising that stilbene derivatives bearing larger substitutions, such as molecules 1, 2, 6-11, and longistilines 12 and 13 proved inactive, as well. Similar to piceatannol, the comparison between structure and activity of $\mathbf{1 4}$ and $\mathbf{1 5}$ further highlights the key role of polyphenols in providing anti-HIV activity.

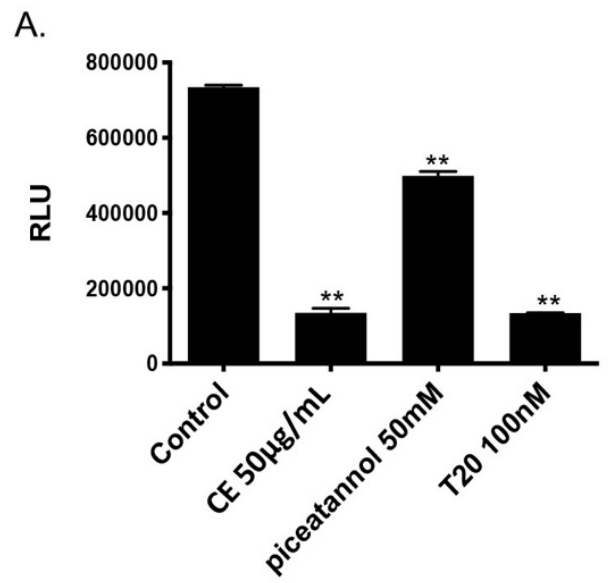

B.

a.

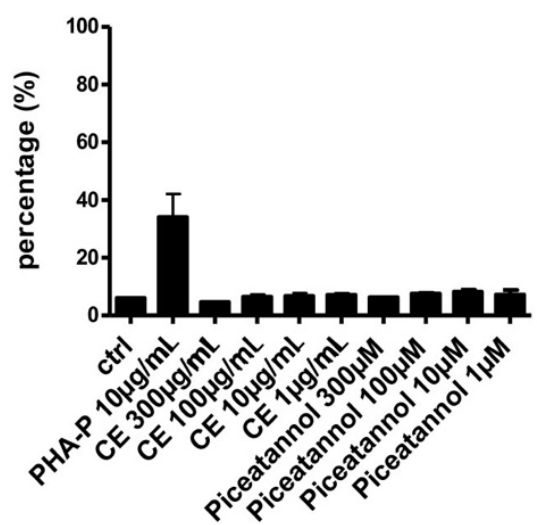

b.

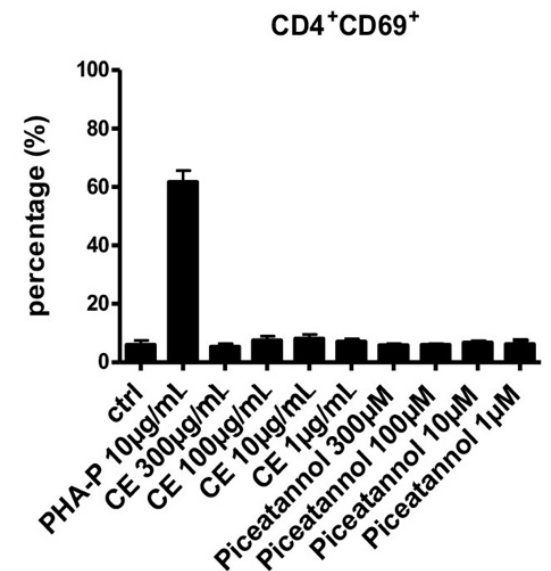

Figure 5. Evaluation of Piceatannol as a microbicide. (A) CE, piceatannol and T20 were tested in a dual chamber system. Compounds and HIV-1 ADA-M viruses were added to Hela cells in the upper chamber. Luciferase of TZM-bl cells in the lower chamber was measured at $24 \mathrm{~h}$ post-infection. (B) Expressions of CD25 (a) and CD69 (b) on PBMCs with or without $\mathrm{CE}$ and piceatannol treatment were measured by flow cytometry. ANOVA analysis was performed for statistical significance. ${ }^{* *} p<0.01$. 


\begin{tabular}{|c|c|c|c|c|c|c|c|c|c|}
\hline & $\mathrm{mol}$ & $\mathbf{R}_{1}$ & $\mathbf{R}_{2}$ & $\mathbf{R}_{\mathbf{2}}{ }^{\prime}$ & $\mathbf{R}_{3}$ & $\mathbf{R}_{\mathbf{3}}{ }^{\prime}$ & $\mathbf{R}_{\mathbf{4}}$ & $\mathbf{R}_{\mathbf{5}}$ & $\mathbf{R}_{6}$ \\
\hline & 1 & $\mathrm{H}$ & $\mathrm{OCH}_{3}$ & $\mathrm{OCH}_{3}$ & $\mathrm{H}$ & $\mathrm{H}$ & $\mathrm{H}$ & $\mathrm{H}$ & $\mathrm{OH}$ \\
\hline & 2 & $\mathrm{H}$ & $\mathrm{OCOCH}_{3}$ & $\mathrm{OCOCH}_{3}$ & $\mathrm{H}$ & $\mathrm{H}$ & $\mathrm{H}$ & $\mathrm{H}$ & $\mathrm{OCOCH}_{3}$ \\
\hline & 3 & $\mathrm{H}$ & $\mathrm{OH}$ & $\mathrm{OH}$ & H & H & $\mathrm{H}$ & H & $\mathrm{OCH}_{3}$ \\
\hline & 4 & $\mathrm{H}$ & $\mathrm{OH}$ & $\mathrm{OH}$ & $\mathrm{H}$ & H & $\mathrm{OH}$ & H & $\mathrm{OH}$ \\
\hline & 5 & $\mathrm{H}$ & $\mathrm{OH}$ & $\mathrm{OH}$ & $\mathrm{H}$ & $\mathrm{H}$ & $\mathrm{H}$ & $\mathrm{OCH}_{3}$ & $\mathrm{OH}$ \\
\hline & 6 & $\mathrm{H}$ & $\mathrm{OCH}_{3}$ & $\mathrm{OCH}_{3}$ & $\mathrm{H}$ & H & $\mathrm{H}$ & $\mathrm{OCH}_{3}$ & $\mathrm{OCH}_{3}$ \\
\hline & 7 & H & $\mathrm{OCH}_{3}$ & $\mathrm{H}$ & H & H & $\mathrm{H}$ & $\mathrm{H}$ & $\mathrm{OH}$ \\
\hline & 8 & $\mathrm{OH}$ & $\mathrm{OCH}_{3}$ & $\mathrm{H}$ & $\mathrm{H}$ & $\mathrm{H}$ & $\mathrm{H}$ & $\mathrm{H}$ & $\mathrm{H}$ \\
\hline $\mathrm{R}_{6}$ & 9 & $\mathrm{H}$ & $\mathrm{OH}$ & $\mathrm{H}$ & $\mathrm{H}$ & $\mathrm{H}$ & $\mathrm{H}$ & $\mathrm{H}$ & $\mathrm{H}$ \\
\hline $1-13$ & 10 & $\mathrm{OCH}_{3}$ & $\mathrm{OCH}_{3}$ & $\mathrm{H}$ & $\mathrm{H}$ & $\mathrm{H}$ & $\mathrm{H}$ & $\mathrm{OCH}_{3}$ & $\mathrm{OCH}_{3}$ \\
\hline & 11 & $\mathrm{H}$ & $\mathrm{OCH}_{3}$ & $\mathrm{OH}$ & $\mathrm{H}$ & $\mathrm{H}$ & $\mathrm{H}$ & $\mathrm{H}$ & $\mathrm{OH}$ \\
\hline & 12 & $\mathrm{H}$ & $\mathrm{OH}$ & $\mathrm{OH}$ & prenyl & prenyl & $\mathrm{H}$ & H & $\mathrm{H}$ \\
\hline & 13 & $\mathrm{H}$ & $\mathrm{OH}$ & $\mathrm{OCH}_{3}$ & $\mathrm{H}$ & prenyl & $\mathrm{H}$ & H & $\mathrm{H}$ \\
\hline
\end{tabular}<smiles>[R]c1cc(O)ccc1-c1cc(=O)c2c(O)c([R])c(O)cc2o1</smiles>

14 (Hispidulin): $\mathrm{R}_{1}=\mathrm{OCH} 3 ; \mathrm{R}_{2}=\mathrm{H}$ 15 (Norartocarpetin): $\mathrm{R}_{1}=\mathrm{H} ; \mathrm{R}_{2}=\mathrm{OH}$ IC50 $=39 \pm 5 \mu \mathrm{M}$

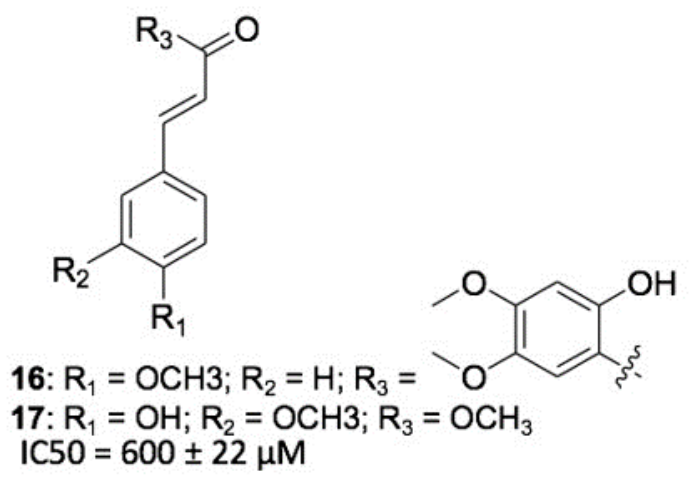

Figure 6. SAR of piceatannol. The chemical structure of compounds 1-17 used to afford SAR of piceatannol is shown. Molecules are grouped based on their chemical structures: (i) stilbene derivatives 1-13; (ii) flavones 14 and 15; (iii) styrene derivatives 16 and 17. $\mathrm{IC}_{50}$ values of the compounds are mentioned when the compound displayed anti-HIV-1 activity.

\subsection{Mode of Action of the Two Flavonoids Inhibiting HIV-1 Entry}

To develop the mode of action, we first performed a ligand-based studies to provide insights into the mechanism of action of piceatannol, norartocarpetin, cassiabrevone, and 4'7-Dihydroxyflavan (4,6)-3, 4', 5,7- tetrahydroxyflavan using the Rapid Overlay of Chemical Structures (ROCS) program (OpenEye Scientific Software). As shown in Figure 7A, a normalized similarity of 0.63 was obtained by comparing piceatannol to norartocarpetin, suggesting that these compounds cover a highly similar pharmacophoric and 3D space. In contrast, $4^{\prime} 7$-dihydroxyflavan (4,6)-3, 4', 5,7- tetrahydroxyflavan and cassiabrevone share a moderate similarity with piceatannol, (normalized similarity $=0.37$ and 0.23 , respectively, Figure 7B-C), which suggests a different mechanism of action for these molecules compared to piceatannol and norartocarpetin. 
A

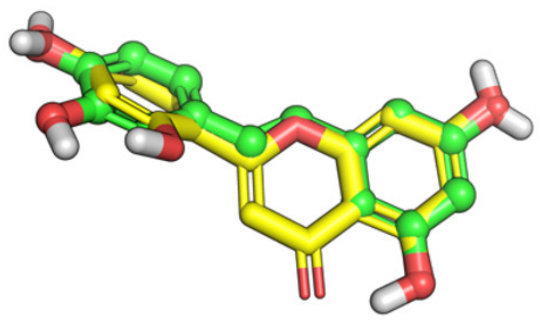

TanimotoCombo $=1.256$

Normalized similarity $=0.63$

B

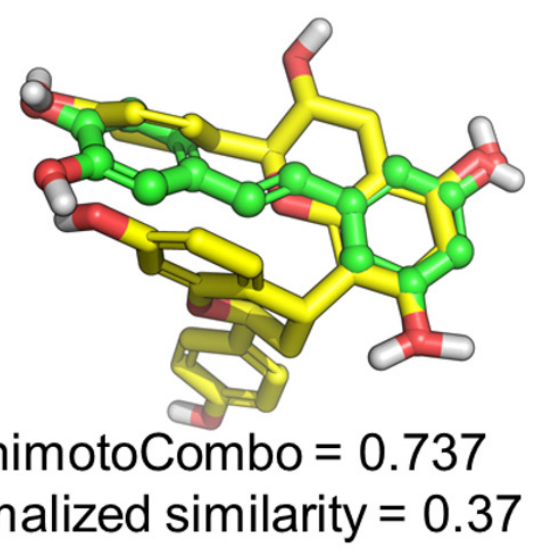

C

\author{
TanimotoCombo $=0.737$ \\ Normalized similarity $=0.37$
}

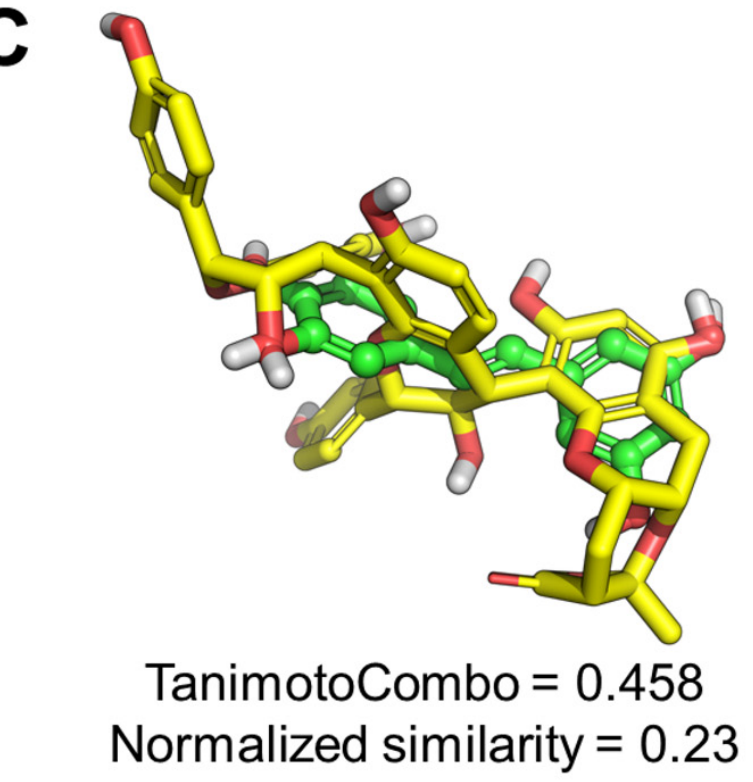

Figure 7. Pharmacophoric studies. (A) ROCS alignment between the query built on piceatannol and norartocarpetin, 4'7-Dihydroxyflavan (4,6)-3, 4', 5,7- tetrahydroxyflavan (B), and cassiabrevone (C). Piceatannol is shown as green balls and sticks with the same orientation in the three panels. Aligned ligands are shown as yellow sticks. Non-polar H atoms were omitted. The TanimotoCombo and normalized similarity scores are reported for each pair of compounds.

For further validation, we then tested cassiabrevone and guibourtinidol-( $4 \alpha \rightarrow 8)$ epiafzelechin in a fusion assay and showed that both two compounds inhibited viral fusion similarly to CE (Figure $8 \mathrm{~A}$ ). Moreover, cassiabrevone but not guibourtinidol- $(4 \alpha \rightarrow 8)$ epiafzelechin inhibited significantly gp120/CD4 binding activity in a dose-dependent 
manner as observed for CE (Figure 8B), indicating that cassiabrevone may play the major role of the crude extract of $C$. abbreviata and display different mode of action from piceatannol (Figure 3D).

A.

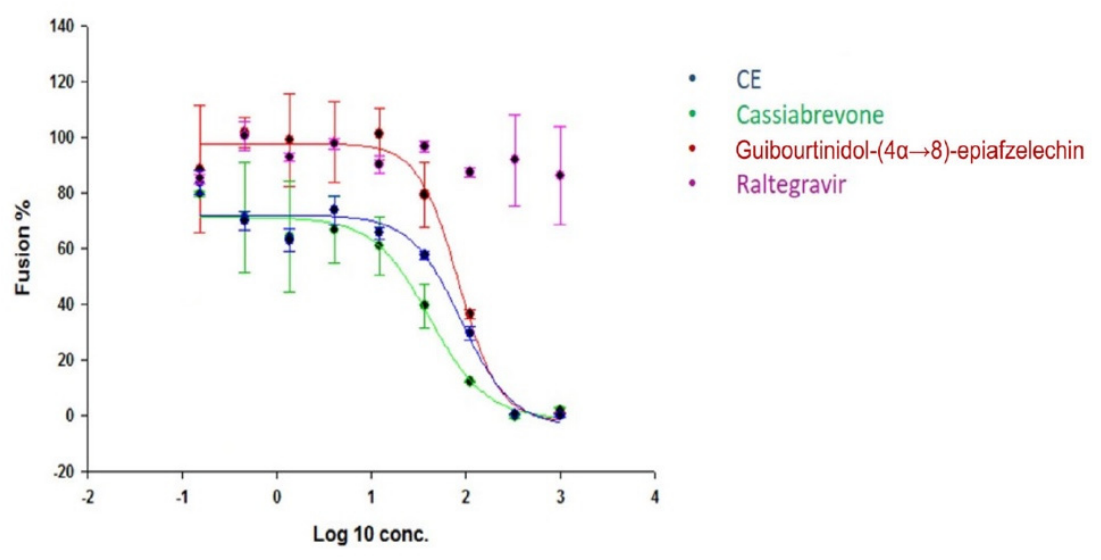

B.

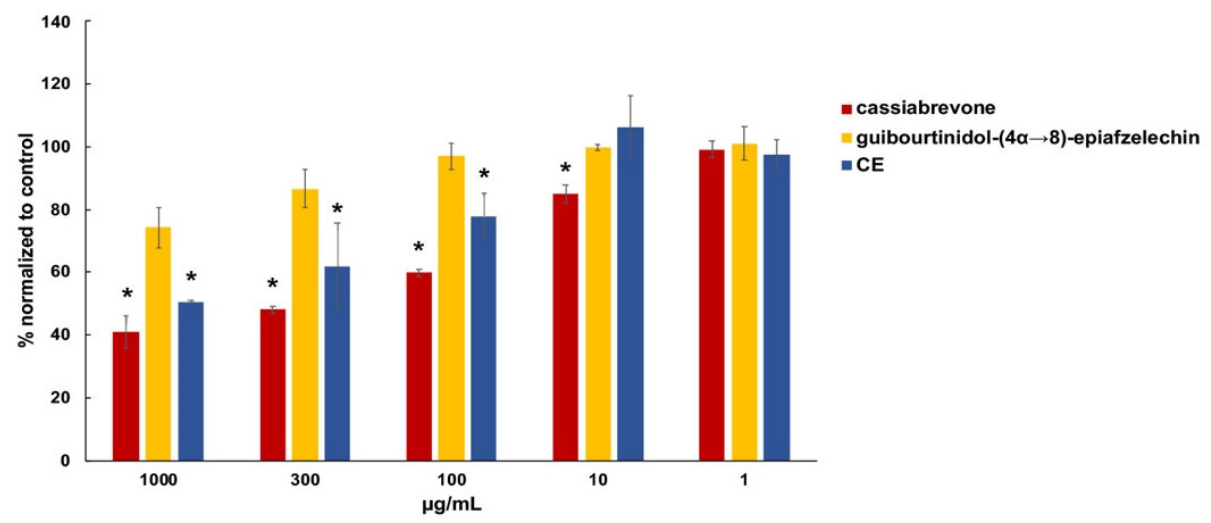

Figure 8. Cassiabrevone inhibits gp120/CD4 interaction. (A) Hela-P4-CXCR4 cells pretreated with $\mathrm{CE}$, guibourtinidol-( $4 \alpha \rightarrow 8)$-epiafzelechin), and cassiabrevone were incubated with hela-ENV-Lai cells. $\beta$-Galactosidase activity was accessed. Data were normalized to control cells without any drugs to give the percentage of fusion. (B) Cassiabrevone and guibourtinidol-( $4 \alpha \rightarrow 8)$ - -epiafzelechin were tested in an in-house ELISA assay against gp120 binding activity. Data were normalized to control cells without compound treatment. ANOVA analysis was performed for statistical significance. * $p<0.05$.

Finally, taken together, our studies confirmed that the traditional medicine plant $C$. abbreviata displayed anti-HIV-1 activity and identified six active components that inhibits HIV-1 entry. Importantly, we revealed a novel compound cassiabrevone and showed that cassiabrevone played the major role of the crude extract of C. abbreviata. Moreover, we delineated the anti-HIV mechanism of piceatannol and showed its potential as a microbicide.

\section{Discussion}

Many antiviral agents have been identified from plant sources but their mechanisms of action are poorly understood. C. abbreviata is indigenous to Africa, and commonly used against infectious diseases $[9,11]$. Nevertheless, C. abbreviata's bioactive compounds were not characterized. The anti-HIV-1 activity of a C. abbreviata's ethanol extract was first described by Leteane's group [13]. In our study, we have performed a secondary ethyl acetate partition after a primary ethanol extraction to obtain a crude extract (CE) with enhanced anti-HIV-1 activity and lower cytotoxicity. We sought here (i) to determine 
at which step of infection the CE of C. abbreviata inhibited HIV-1, (ii) to screen active compounds against HIV-1 entry, and (iii) to unravel the mechanism of action of isolated compounds preventing HIV-1 entry.

Our results indicate that CE inhibited HIV-1 infection at an early stage of the HIV-1 entry process independent of co-receptor usage and interacted with HIV-1 gp120. By testing compounds only at the time of infection against pseudotyped viruses, we found that oleanolic acid, palmitic acid, taxifolin, and piceatannol inhibited HIV-1 entry at the micromolar range for non-cytotoxic concentrations. These results are consistent with previous studies showing that palmitic acid and oleanolic acid blocked gp120-CD4 interaction [20,21] and that oleanolic acid, piceatannol and taxifolin inhibited HIV-1 infection [22-25]. According to our findings, the major active components of $\mathrm{CE}$ inhibited the interaction between gp120 and CD4, and, especially, cassiabrevone, a flavonoid with a new structure purified from $\mathrm{CE}$, reproduced this feature. CD4 and co-receptor binding sites, as well as variable loops and glycans of gp120, were already proposed as therapeutic targets. For instance, several small-molecule attachment inhibitors targeting the conserved CD4 binding region within gp120 have been described [26-29]. Fostemsavir, a prodrug of the HIV-1 attachment inhibitor temsavir, was recently approved in clinic for heavily treatment-experienced HIV-1 patients. Using homology models, fostemsavir was proposed to bind to the unliganded conformation of gp120 within the structurally conserved outer domain adjacent to the CD4 binding loop. It is tempting to speculate that other compounds derived from natural products may display similar activity on gp120 conformation or binding with CD4. In our hands, cassiabrevone may display such potential and might explain the main effects of $C$. abbreviata against HIV-1 entry.

In this study, we have shown, for the first time, that piceatannol inhibits HIV-1 entry and focused our work to explain its mode of action, as well as its potency as microbicide and against other viruses. Clouser et al. have reported that piceatannol inhibited HIV-1 replication with an $\mathrm{IC}_{50}$ of $21.4 \mu \mathrm{M}$ in accordance with our results [24]. In our hands, time dose-dependent experiments and fusion assays did not support piceatannol as an HIV-1 integrase inhibitor as previously reported in non-cell-based assays [25,30]. We did not find any effect of piceatannol when added after the step of infection in our pseudotype assay although the integrase inhibitor raltegravir inhibited HIV-1 infection when added only after the time of infection (Figure 3). Taking into consideration that piceatannol did not affect neither CD4 and CCR5/CXCR4 binding, nor the interaction between CD4 and gp120, as well as the fusion process, we assume that piceatannol may interact with virus attachment by adsorbing at either the cell surface or the virus surface. Piceatannol also showed a synergistic effect with both co-receptor and fusion inhibitors, which indicates that piceatannol employs a different mechanism to prevent HIV entry. This hypothesis is reinforced by the observation that piceatannol inhibited VSV infection since VSV enters into target cells by endocytosis and not by interfering with a specific cellular receptor. From a chemical standpoint, piceatannol (trans-3, $3^{\prime}, 4,5^{\prime}$-tetrahydroxystilbene) is a natural analogue of resveratrol (trans-3, $4^{\prime}, 5^{\prime}$-trihydroxystilbene). Many analogues of resveratrol have been

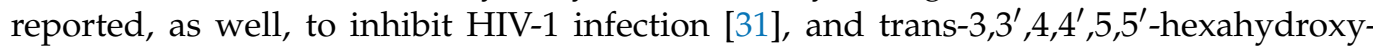
stilbene was shown recently to inhibit HIV-1 entry before the fusion step [32]. Both piceatannol and 3,3' $3^{\prime}, 4^{\prime}, 5,5^{\prime}$-hexahydroxy-trans-stilbene display better anti-HIV activity than resveratrol, suggesting that the additional hydroxyl groups to the basic stilbene rings may increase the anti-HIV activity by strengthening compound affinity or by facilitating its action on the membrane surface. Furthermore curcumin, having two phenols connected by a carbon chain, has structural similarity to piceatannol and can affect viral membrane fluidity to block viral entry [33] similarly to rigid amphipathic fusion inhibitors (RAFIs) and LJ001, which affects the membrane of HIV [7,34]. Interestingly, resveratrol was also shown to inhibit simplex virus vaginal infection in a mouse model [35].

The SAR and ligand-based studies highlighted the highly specific chemical and pharmacophoric features of piceatannol that are required to exert anti-HIV-1 activity. Moreover, the flavone norartocarpetin was identified as a conformational restrained analogue of 
piceatannol endowed with comparable efficacy. Piceatannol and norartocarpetin share a number of pharmacophoric and shape similarities, indicating a common mechanism of action. In contrast, $4^{\prime} 7$-dihydroxyflavan (4,6)-3, 4' $, 5,7$ - tetrahydroxyflavan and cassiabrevone share only a moderate similarity with piceatannol, which suggests that these molecules might inhibit HIV-1 replication through a mechanism that is different from that observed for piceatannol itself and norartocarpetin. The SAR study also emphasized the key role of polyphenols in providing anti-HIV activity, in agreement with recent reports [32,36,37]. One may note that piceatannol has a catechol moiety, widespread in natural products, which is considered as a protein-reactive species [38,39]. However, the anti-HIV-1 effect of piceatannol was found in this work to be highly specific by targeting only the entry step of the envelope virus HIV, HSV, and VSV without significant cytotoxicity.

Importantly, we have shown that both CE and piceatannol inhibited HIV infection in an in vitro dual-chamber model, mimicking the epithelium of the female genital tract [35], suggesting that the active components can cross the epithelial barrier without any toxicity on epithelial cells and no further activation of PBMCs. These data indicate the potential of piceatannol or cassiabrevone to be used as a lead structure for microbicides, although it did not prevent cell-to-cell and DC-SIGN-mediated viral transmission in vitro. In addition, the dual HIV / HSV activity of piceatannol could be crucial for microbicide applications since genital HSV-2 infection has been shown to potentiate HIV transmission and infection [40].

\section{Conclusions}

There is still an ongoing need for new potent classes of antiretroviral drugs with improved safety and tolerability profiles to sustain long-life antiretroviral therapy. In the present work, we have shown that 6 active components block HIV-1 entry. Importantly, we have isolated a novel flavonoid named as cassiabrevone and identified cassiabrevone as one of the active components from C. abbreviata that prevents HIV-1 entry by targeting gp120. Similar to piceatannol, cassiabrevone might have the potential to be used as a microbicide. Optimized synthetic derivatives from cassiabrevone and/or piceatannol should be resolved to reach a future therapeutic efficacy in humans.

\section{Materials and Methods}

\subsection{Plant Extraction and Compounds Purification}

Barks and roots of $C$. abbreviata were collected from mature shrubs in Makueni County, Kenya. Its identity was confirmed by DNA barcoding approach in the lab. All materials were pulverized before extraction. The crude extract (CE) was obtained through a first extraction of barks and roots from C. abbreviata that were pulverized with $95 \%$ ethanol, and a second extraction with ethyl acetate, and dried. The extracts were combined and concentrated to a small volume to provide a crude extract. The concentrate of the ethanol phase was suspended in deionized water, successively partitioned with $\mathrm{CHCl}_{3}, \mathrm{EtOAc}$, and $n$-BuOH and subjected to column chromatography over silica gel. The $\mathrm{CHCl}_{3}$ and EtOAc extracts were combined and subjected to column chromatography over silica gel eluting with a gradient $\mathrm{CHCl}_{3}-\mathrm{MeOH}(0->100 \%)$, followed by column chromatography over octadecyl silane and sephadex LH-20. Preparative thin layer chromatography was used to purify the compounds, and purity over $95 \%$ was verified by HPLC-UV. To characterize the compounds, UV and NMR data were collected from UV-2550 spectrometer and Bruker Avance 500 or 600 NMR spectrometers.

\subsection{Cell Cultures}

MT-4, U373-CD4-CXCR4, U373-CD4-CCR5, HeLa and TZM-Bl cell lines were obtained through the NIH AIDS Reagent Program. HEK 293, Vero, MDCK, and CRFK cells were purchased from ATCC (Manassas, VA, USA). HeLa-P4-CXCR4-LTRLacZ and Hela-ENV-Lai cells [26] were kindly given by Dr. Marc Alizon, Institute Pasteur, Paris. MT-4 cells were cultured in RPMI 1640 (Lonza, Wijchen, The Netherlands) containing 10\% heat-inactivated fetal bovine serum (FBS) (Lonza, Netherlands) and 2mM L-glutamine (Invitrogen, Gos- 
selies, Belgium). U373-CD4-CXCR4 and U373-CD4-CCR5 were cultured in RPMI 1640 containing 10\% FBS, 2mM L-glutamine, $200 \mu \mathrm{g} / \mathrm{mL}$ geneticin (Invitrogen, Belgium), and $100 \mu \mathrm{g} / \mathrm{mL}$ hygromicin B (Invitrogen). HEK 293, Vero, Hela, and TZM-Bl were cultured in dulbecco's modified eagle medium (DMEM) (Lonza) containing 10\% FBS and $2 \mathrm{mM}$ L-glutamine. MDCK and CRFK cells were in eagle's minimum essential medium (Lonza) containing 10\% FBS. HeLa-P4-CXCR4-LTRLacZ cells were cultured in DMEM containing $10 \%$ FBS, $2 \mathrm{mM}$ L-glutamine, and $500 \mu \mathrm{g} / \mathrm{mL}$ geneticin. Hela-ENV-Lai cells were cultured in DMEM containing 10\% FBS, $2 \mathrm{mM}$ L-glutamine, and $2 \mu \mathrm{M}$ methotrexate (Sigma-Aldrich, Liège, Belgium).

\subsection{Viral Infection with HIV-1 Reference Strains and Clinical Isolates}

Peripheral blood mononuclear cells (PBMCs) were isolated from healthy donors' buffy coats (Red Cross of Luxembourg, Luxembourg, Luxembourg) using Ficoll-Hypaque gradient as indicated previously (Sigma-Aldrich, Liège, Belgium). PBMCs were stimulated using $10 \mu \mathrm{g} / \mathrm{mL}$ phytohemagglutinin (PHA-P, Sigma Aldrich) for $48 \mathrm{~h}$ and recombinant IL-2 (10 U /mL, Roche, Sigma-Aldrich, Liège, Belgium) for another $24 \mathrm{~h}$. Stimulated PBMCs were infected by the HIV-1 reference strains IIIB/ADA-M or primary clinical isolates expanded in culture from anonymized left-over samples (Centre Hospitalier de Luxembourg, Luxembourg, Luxembourg) in the presence or absence of drugs replaced every other day during 7 days. P24 production was measured in supernatants by ELISA (Perkin Elmer, Brussels, Belgium). Efavirenz (EFV) and azidothymidine (AZT) were obtained from Sigma_Aldrich. Enfuvirtide (T20) was purchased from Eurogentec (Seraing, Belgium).

\subsection{Cytotoxicity and Apoptosis Assays}

To assess drug cytotoxicity, PBMCs were incubated with or without drugs in a 96-well round bottom plate (Thermo Fisher, Asse, Belgium) at $2 \times 10^{5} / 200 \mu \mathrm{L} /$ well. After 2 days, cells were washed with PBS and stained with $0.1 \mu \mathrm{L}$ near-IR fluorescent reactive dye (Life technologies, Ghent, Belgium) in $100 \mu \mathrm{L}$ PBS for $20 \mathrm{~min}$ at room temperature in dark. Stained cells were measured by flow cytometry (FACSCanto, BD biosciences, Belgium).

To measure apoptosis, PBMCs were incubated with or without drugs in a 96-well round bottom plate at $2 \times 10^{5} / 200 \mu \mathrm{L} /$ well. After 2 days, cells were washed with PBS and stained with $2.5 \mu \mathrm{L}$ Annexin-V-APC (Biosciences, Aalst, Belgium) in $100 \mu \mathrm{L}$ staining buffer containing $10 \mathrm{mmol} / \mathrm{L}$ HEPES pH7.4, $140 \mathrm{mmol} / \mathrm{L} \mathrm{NaCl}$, and $2.5 \mathrm{mmol} / \mathrm{L} \mathrm{CaCl}_{2}$ for $20 \mathrm{~min}$ at room temperature in dark. Cells were then washed with staining buffer and incubated with $100 \mu \mathrm{L} 0.1 \mu \mathrm{g} / \mathrm{mL}$ propidium iodide (PI) (Thermo Fisher, Asse, Belgium) for $5 \mathrm{~min}$ at room temperature in dark. Stained cells were measured by flow cytometry (FACSCanto, BD, Aalst, Belgium).

\subsection{Multi-Dosing Time Assay and Drug Combination Assay}

For normal treatment, U373-CD4-CXCR4/U373-CD4-CCR5 cells were infected by pseudotyped virus pNL4.3 $\triangle$ EnvLuc-HXB2/pNL4.3 $\triangle E n v L u c-B A L$ [41], respectively, in the presence or absence of drugs through $2 \mathrm{~h}$ spinoculation at $1200 \times \mathrm{g}$. After infection, cells were then cultured in fresh culture medium for $48 \mathrm{~h}$. Luciferase activity in cell lysates expressed as relative light units was measured via Luciferase System kit (Promega, Leiden, Netherlands).

In multi-dosing time assay, four different treatments were performed: $2 \mathrm{~h}$ pre-incubation of drugs on U373-CD4-CXCR4/U373-CD4-CCR5 cells, $2 \mathrm{~h}$ pre-incubation of drugs on pseu-

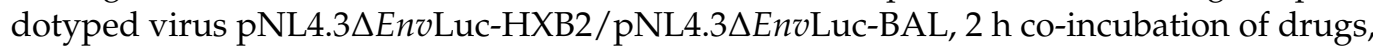
cells and viruses during spinoculation (normal treatment), and $2 \mathrm{~h}$ incubation of drugs on infected cells after spinoculation (post-infection).

In drug combination assay, U373-CD4-CXCR4/U373-CD4-CCR5 cells were co-incubated with CE or piceatannol combined with the CXCR4 inhibitor AMD3100 (Sigma, Belgium) or with the CCR5 inhibitor Maraviroc (Sigma, Belgium) or with the fusion inhibitor T20 during infection with the pseudotyped viruses by spinoculation as described above (normal 
treatment). The combination index (CI) was calculated at the $\mathrm{EC}_{95}$-level using CompuSyn software (ComboSyn, USA). According to Chou and Talalay's method, CI > 1.1 means antagonism, $\mathrm{CI}<0.9$ means synergy, and $0.9<\mathrm{CI}<1.1$ means additive effect of the drugs.

\subsection{Fusion Assay}

Fusion inhibition was evaluated as previously described [26]. Briefly, HeLa-ENV-Lai cells were pre-incubated with or without drugs for $2 \mathrm{~h}$ and added to HeLa-P4-CXCR4LTRLacZ cells which were placed in a 96-well plate 1 day before. After $24 \mathrm{~h}$, cells were washed with PBS and then incubated with $50 \mu \mathrm{L}$ containing 0.5\% NP-40 (Sigma, Belgium) for $15 \mathrm{~min}$ at room temperature. Fifty microliters chlorophenol red- $\beta$-D-galactopyranoside (CPRG) reagent (Roche, Sigma-Aldrich, Liège, Belgium) was then added into the plate. After 30 min incubation at room temperature in dark, $\beta$-galactosidase was assessed by measuring $\mathrm{OD}_{562}$ of the cells via POLARstar Omega plate reader (BMG Labtech, Ortenberg, Germany).

\subsection{Broad Spectrum Antiviral Activity}

Antiviral assays were previously described [27] for the following viruses: HSV-1 (KOS), HSV-2 G, HSV-1 TK KOS ACV; VSV, coxsackie virus B4, RSV, Coxsackie virus B4, parainfluenza- 3 virus, reovirus-1, sindbisvirus, punta toro virus, yellow fever virus, influenza A/H1N1 A/Ned/378/05, influenza A/H3N2 A/HK/7/87, influenza B B/Ned/537/05; human corona virus, feline corona virus, feline herpes virus, and HCV (Jc1).

\subsection{CD4-gp120 Interaction Assay}

Human soluble CD4 (sCD4) was immobilized in a 96-well plate by adding $100 \mathrm{ng}$ sCD4 (R\&D Systems, Belgium) in $100 \mu \mathrm{L}$ PBS per well and incubated at $4{ }^{\circ} \mathrm{C}$. After $24 \mathrm{~h}$, the CD4 coated plate was washed with $1 \%$ BSA-PBS and blocked by adding $100 \mu \mathrm{L} 5 \%$ BSA-PBS per well for $1 \mathrm{~h}$ at $4{ }^{\circ} \mathrm{C}$. The coated plate was then washed and incubated with or without drugs for $1 \mathrm{~h}$ at $4{ }^{\circ} \mathrm{C}$. After washing, $100 \mathrm{ng}$ HIV-1 gp120 protein (Fitzgerald, Acton, MA, USA) was added into the plate and kept for $1 \mathrm{~h}$ at $4{ }^{\circ} \mathrm{C}$. The plate was washed, and anti-HIV-1 gp120 (Aalto Bio Reagents, Dublin, Ireland) (100 ng/100 $\mu \mathrm{L}$ PBS) was added. After $1 \mathrm{~h}$, the plate was washed and anti-sheep HRP (Sigma, Belgium) $(100 \mathrm{ng} / 100 \mu \mathrm{L}$ PBS) was added. After $1 \mathrm{~h}$ incubation at $4{ }^{\circ} \mathrm{C}, 100 \mu \mathrm{L}$ o-phenylenediamine dihydrochloride (OPD) (Thermo Fisher, Asse, Belgium) was added and incubated for $20 \mathrm{~min}$ in dark. One hundred microliters $0.5 \mathrm{M} \mathrm{H}_{2} \mathrm{SO}_{4}$ was finally added to stop the reaction. $\mathrm{OD}_{492}$ and $\mathrm{OD}_{630}$ were measured by POLARstart Omega Plate Reader. $\mathrm{OD}_{492}-\mathrm{OD}_{630}$ was calculated.

\subsection{Binding Assays and Co-Receptor Internalization}

Binding competition between increasing concentrations of compounds and FITCconjugated mouse anti-human CD4 clone RPA-4 (Biolegend, Amsterdam, Netherlands), PE-conjugated mouse anti-Human CXCR4 clone 12G5, and PE-conjugated mouse antihuman CCR5 clone 2D7 (BD Pharma, Aalst, Belgium) to U373-CD4-CXCR4 and U373-CD4CCR5 cells was first tested by flow cytometry (FACSCanto). The chemokines CXCL12 and CCL5 (50 nM) (Peprotech, London, United Kingdom) were used as positive controls, and near-IR fluorescent reactive dye was added simultaneously to evaluate cell viability. After $1 \mathrm{~h}$ of incubation at $4{ }^{\circ} \mathrm{C}$, cells were washed with FACS buffer $(1 \%$ bovine serum albumin, $0.1 \%$ N3Na in PBS, Sigma), and Mean Fluorescence Intensity (MFI) was measured. To study co-receptor internalization, compounds were incubated alone (agonist mode) or in the presence of $50 \mathrm{nM}$ chemokines (CXCL12/CCL5) (antagonist mode) with MT-4 and U373-CD4-CCR5 cells at $37^{\circ} \mathrm{C}$ for $1 \mathrm{~h}$. Internalization was stopped after $30 \mathrm{~min}$ by addition of $\mathrm{NaN}_{3}(0.1 \%)$ on ice. Cells were stained with anti-human CXCR4 clone 4G10 (BD, Belgium) or anti-human CCR5 (CD195) clone T21/8, (eBioscience, Asse, Belgium), Near-IR fluorescent reactive dye during $1 \mathrm{~h}$ at $4{ }^{\circ} \mathrm{C}$, washed with FACS buffer, and a secondary PEconjugated goat anti-mouse antibody (Jackson ImmunoResearch, West Grove, PA, USA). 


\subsection{Dual-Chamber and DC-SIGN Transmission Assays}

Dual chamber transmission assay was performed as previously described [28]. HeLa cells were seeded into an upper chamber of a transwell plate (Sigma-Aldrich, Liège, Belgium), while TZM-bl cells were seeded in the lower chamber. Trans Epithelial Electric Resistance (TEER) was measured using Millicell-ERS Volt-Ohm Meter. HIV-1 ADA-M (200 pg) and drugs were added to the upper chamber after 4 days when TEER reached $150 \mathrm{Ohm} / \mathrm{cm}^{2} .24 \mathrm{~h}$ after infection luciferase value of TZM-bl cells lysate was measured using the Luciferase System Kit and the POLARstar Omega Plate Reader. Data were analyzed using GraphPrism. The HIV-1 DC-SIGN transmission assay was performed as previously described [27]. To investigate the cellular activation induced by CE or piceatannol, CD25 and CD69 expression was measured on PBMCs after incubation with CE/piceatannol or $10 \mu \mathrm{g} / \mathrm{mL}$ PHA-P for $24 \mathrm{~h}$ at $37^{\circ} \mathrm{C}$ using FITC-conjugated anti-CD4, PE/Cy7-conjugated anti-CD25, PE-conjugated anti-CD69 mAbs (Biolegend, Amsterdam, Netherlands), and the near-IR fluorescent reactive dye.

\subsection{In Silico Ligand-Based Study}

For SAR purposes, molecules 1-11 were purchased from MolPort (Riga, Latvia), while molecules 12-17 (purity > 95\% by HPLC) were retrieved from an in-house library of natural products previously characterized [29,42]. To provide insights into the mechanism of action of bioactive hits, a ligand-based study was conducted using the ROCS program (Openeye Scientific Software) version 3.3.0.3 [43]. A query was built on the chemical structure of piceatannol and used to screen the conformational database of compounds 1-17 that was generated by OMEGA (OpenEye Scientific Software) version 3.1.0.3 [44] using default settings. Ligands similarity was assessed by the TanimotoCombo scores, while normalized similarity scores were calculated by dividing the TanimotoCombo value by two. All the possible stereochemical configurations of cassiabrevone and $4^{\prime} 7$-Dihydroxyflavan $(4,6)-3,4{ }^{\prime}, 5,7-$ tetrahydroxyflavan were analyzed; the reported normalized similarity and TanimotoCombo scores refer to the isomers endowed with the highest similarity to piceatannol.

Author Contributions: Y.Z. performed all anti-HIV-1 experiments, analyzed the data, and wrote the manuscript. X.Y. and A.S. purified the active compounds from C. abbreviata, D.S. performed the screening of the crude extract and piceatannol against various viruses, M.M. (Mattia Mori) and B.B. performed the in silico ligand-based studies, A.C. performed the binding assays and co-receptor internalization, M.M. (Martin Mulinge). provided the barks of C. abbreviata and set-up the extraction of the plant with A.S., J.C.S provided the clinical samples and designed the study, and C.S.-D. designed the study, analyzed the data, and wrote the manuscript. All authors contributed to the article and approved the submitted version.

Funding: This work was supported by the "Fonds National de la Recherche" of Luxembourg [PHD AFR grant 1189522], "la Fondation Recherche sur le SIDA", the KU Leuven (GOA 10/014 and PF/10/018), the Foundation of Scientific Research (FWO no. G-0528-12), and the Luxembourg Institute of Health (MESR grant 20150415).

Institutional Review Board Statement: Ethical review and approval were waived for this study, due to the use of anonymized left over clinical primary viral strains or PBMCs from the red Blood cross of Luxembourg that did not require both ethical approval.

Informed Consent Statement: Inform consents were waived for this study, due to the use of anonymized left over clinical primary viral strains or PBMCs from the red Blood cross of Luxembourg that did not require both inform consents of the patients.

Data Availability Statement: All the data are contained within the article.

Acknowledgments: Authors thank Sandra Claes, Evelyne Van Kerckhove, Eric Fonteyn, Leentje Persoons, Lies Van den Heurck (died 3 September 2018), Morgane Lemaire, Jean-Yves Servais, Manuel Counson, and Gilles Iserentant for excellent technical assistance. Authors acknowledge networking contribution by the COST Action CM1407 "Challenging organic syntheses inspired by 
nature-from natural products chemistry to drug discovery". MM wish to thank the OpenEye Free Academic Licensing Program for providing a free academic license for molecular modeling and chemoinformatics software.

Conflicts of Interest: The authors declare no conflict of interest.

\section{References}

1. Este, J.A.; Cihlar, T. Current status and challenges of antiretroviral research and therapy. Antivir. Res. 2010, 85, 25-33. [CrossRef]

2. Palmisano, L.; Vella, S. A brief history of antiretroviral therapy of HIV infection: Success and challenges. Ann. Ist. Super Sanita 2011, 47, 44-48. [PubMed]

3. Glynn, J.R.; Carael, M.; Auvert, B.; Kahindo, M.; Chege, J.; Musonda, R.; Kaona, F.; Buve, A. Study Group on the Heterogeneity of, H.I.V.E. i. A. C., Why do young women have a much higher prevalence of HIV than young men? A study in Kisumu, Kenya and Ndola, Zambia. AIDS 2001, 15 (Suppl. 4), S51-S60. [CrossRef] [PubMed]

4. Mehellou, Y.; De Clercq, E. Twenty-six years of anti-HIV drug discovery: Where do we stand and where do we go? J. Med. Chem. 2010, 53, 521-538. [CrossRef] [PubMed]

5. Vigant, F.; Santos, N.C.; Lee, B. Broad-spectrum antivirals against viral fusion. Nat. Rev. Microbiol. 2015, 13, 426-437. [CrossRef]

6. Wilen, C.B.; Tilton, J.C.; Doms, R.W. HIV: Cell binding and entry. Cold Spring Harb. Perspect. Med. 2012, 2, a006866. [CrossRef]

7. St Vincent, M.R.; Colpitts, C.C.; Ustinov, A.V.; Muqadas, M.; Joyce, M.A.; Barsby, N.L.; Epand, R.F.; Epand, R.M.; Khramyshev, S.A.; Valueva, O.A.; et al. Rigid amphipathic fusion inhibitors, small molecule antiviral compounds against enveloped viruses. Proc. Natl. Acad. Sci. USA 2010, 107, 17339-17344. [CrossRef]

8. Dias, D.A.; Urban, S.; Roessner, U. A historical overview of natural products in drug discovery. Metabolites 2012, 2, 303-336. [CrossRef] [PubMed]

9. Maurice, M.I. Handbook of African Medicinal Plants, 2nd ed.; CRC Press: Boca Raton, FL, USA, 1993.

10. Mongalo, N.I.; Mafoko, B.J. Cassia abbreviata Oliv, a review of its ethnomedicinal uses, toxicology, phytochemistry, possible propagation techniques and pharmacology. Afr. J. Pharm. Pharmacol. 2013, 7, 6.

11. Ribeiro, A.; Romeiras, M.M.; Tavares, J.; Faria, M.T. Ethnobotanical survey in Canhane village, district of Massingir, Mozambique: Medicinal plants and traditional knowledge. J. Ethnobiol. Ethnomed. 2010, 6, 33.

12. Yang, X.; He, Z.; Zheng, Y.; Wang, N.; Mulinge, M.; Schmit, J.C.; Steinmetz, A.; Seguin-Devaux, C. Chemical Constituents of Cassia abbreviata and Their Anti-HIV-1 Activity. Molecules 2021, 26, 2455. [CrossRef]

13. Leteane, M.M.; Ngwenya, B.N.; Muzila, M.; Namushe, A.; Mwinga, J.; Musonda, R.; Moyo, S.; Mengestu, Y.B.; Abegaz, B.M.; Andrae-Marobela, K. Old plants newly discovered: Cassia sieberiana D.C. and Cassia abbreviata Oliv. Oliv. root extracts inhibit in vitro HIV-1c replication in peripheral blood mononuclear cells (PBMCs) by different modes of action. J. Ethnopharmacol. 2012, 141, 48-56. [CrossRef]

14. Chou, T.C. Drug combination studies and their synergy quantification using the Chou-Talalay method. Cancer Res. 2010, 70, 440-446. [PubMed]

15. Cirigliano, A.; Stirpe, A.; Menta, S.; Mori, M.; Dell'Edera, D.; Pick, E.; Negri, R.; Botta, B.; Rinaldi, T. Yeast as a tool to select inhibitors of the cullin deneddylating enzyme Csn5. J. Enzym. Inhib. Med. Chem. 2016, 31, 1632-1637. [CrossRef] [PubMed]

16. Ghirga, F.; Quaglio, D.; Mori, M.; Cammarone, S.; Iazzetti, A.; Goggiamani, A.; Ingallina, C.; Botta, B.; Calcaterra, A. A unique high-diversity natural product collection as a reservoir of new therapeutic leads. Org. Chem. Front. 2021, 8, 996-1025. [CrossRef]

17. Infante, P.; Alfonsi, R.; Ingallina, C.; Quaglio, D.; Ghirga, F.; D'Acquarica, I.; Bernardi, F.; Di Magno, L.; Canettieri, G.; Screpanti, I.; et al. Inhibition of Hedgehog-dependent tumors and cancer stem cells by a newly identified naturally occurring chemotype. Cell Death Dis. 2016, 7, e2376.

18. Infante, P.; Mori, M.; Alfonsi, R.; Ghirga, F.; Aiello, F.; Toscano, S.; Ingallina, C.; Siler, M.; Cucchi, D.; Po, A.; et al. Gli1/DNA interaction is a druggable target for Hedgehog-dependent tumors. EMBO J. 2015, 34, 200-217. [CrossRef] [PubMed]

19. Mascarello, A.; Mori, M.; Chiaradia-Delatorre, L.D.; Menegatti, A.C.; Delle Monache, F.; Ferrari, F.; Yunes, R.A.; Nunes, R.J.; Terenzi, H.; Botta, B.; et al. Discovery of Mycobacterium tuberculosis protein tyrosine phosphatase B (PtpB) inhibitors from natural products. PLoS ONE 2013, 8, e77081.

20. Lee, D.Y.; Lin, X.; Paskaleva, E.E.; Liu, Y.; Puttamadappa, S.S.; Thornber, C.; Drake, J.R.; Habulin, M.; Shekhtman, A.; Canki, M. Palmitic Acid Is a Novel CD4 Fusion Inhibitor That Blocks HIV Entry and Infection. Aids Res. Hum. Retrovir. 2009, 25, 1231-1241. [PubMed]

21. Harada, S.; Ogihara, K.; Hikichi, Y.; Matano, T.; Narumi, K.Y. Oleanolic acid derivative OKS3-019 as a novel bifunctional HIV-1 entry inhibitor. In Proceedings of the Conference on Retroviruses and Opportunistic Infections, Seattle, WA, USA, 13-16 February 2017.

22. Clouser, C.L.; Chauhan, J.; Bess, M.A.; van Oploo, J.L.; Zhou, D.; Dimick-Gray, S.; Mansky, L.M.; Patterson, S.E. Anti-HIV-1 activity of resveratrol derivatives and synergistic inhibition of HIV-1 by the combination of resveratrol and decitabine. Bioorg. Med. Chem. Lett. 2012, 22, 6642-6646.

23. Kashiwada, Y.; Wang, H.K.; Nagao, T.; Kitanaka, S.; Yasuda, I.; Fujioka, T.; Yamagishi, T.; Cosentino, L.M.; Kozuka, M.; Okabe, H.; et al. Anti-AIDS agents. 30. Anti-HIV activity of oleanolic acid, pomolic acid, and structurally related triterpenoids. J. Nat. Prod. 1998, 61, 1090-1095. [CrossRef] [PubMed] 
24. Mengoni, F.; Lichtner, M.; Battinelli, L.; Marzi, M.; Mastroianni, C.M.; Vullo, V.; Mazzanti, G. In vitro anti-HIV activity of oleanolic acid on infected human mononuclear cells. Planta Med. 2002, 68, 111-114. [CrossRef] [PubMed]

25. Min, B.S.; Lee, H.K.; Lee, S.M.; Kim, Y.H.; Bae, K.H.; Otake, T.; Nakamura, N.; Hattori, M. Anti-human immunodeficiency virus-type 1 activity of constituents from Juglans mandshurica. Arch Pharm. Res. 2002, 25, 441-445. [CrossRef] [PubMed]

26. Bar, S.; Alizon, M. Role of the ectodomain of the gp41 transmembrane envelope protein of human immunodeficiency virus type 1 in late steps of the membrane fusion process. J. Virol. 2004, 78, 811-820. [CrossRef]

27. Gordts, S.C.; Ferir, G.; D’Huys, T.; Petrova, M.I.; Lebeer, S.; Snoeck, R.; Andrei, G.; Schols, D. The Low-Cost Compound Lignosulfonic Acid (LA) Exhibits Broad-Spectrum Anti-HIV and Anti-HSV Activity and Has Potential for Microbicidal Applications. PLoS ONE 2015, 10, e0131219. [CrossRef]

28. Pasetto, S.; Pardi, V.; Murata, R.M. Anti-HIV-1 activity of flavonoid myricetin on HIV-1 infection in a dual-chamber in vitro model. PLoS ONE 2014, 9, e115323. [CrossRef]

29. Sakamoto, Y.; Ohmoto, N.; Tamotsu, K.; Tomimori, T.; Miyaichi, Y.; Shirataki, Y.; Monache, F.; Botta, B. On the relationship between the chemical structure and the cyclic AMP phosphodiesterase inhibitory activity of flavonoids as studied by carbon13 NMR. Bull. Chem. Soc. Jpn. 1989, 62, 2450-2452. [CrossRef]

30. Panthong, P.; Bunluepuech, K.; Boonnak, N.; Chaniad, P.; Pianwanit, S.; Wattanapiromsakul, C.; Tewtrakul, S. Anti-HIV-1 integrase activity and molecular docking of compounds from Albizia procera bark. Pharm. Biol. 2015, 53, 1861-1866. [CrossRef]

31. Piao, Z.S.; Feng, Y.B.; Wang, L.; Zhang, X.Q.; Lin, M. Synthesis and HIV-1 inhibitory activity of natural products isolated from Gnetum parvifolium and their analogues. Yao Xue Xue Bao 2010, 45, 1509-1515.

32. Han, Y.S.; Quashie, P.K.; Mesplede, T.; Xu, H.; Quan, Y.; Jaeger, W.; Szekeres, T.; Wainberg, M.A. A resveratrol analog termed 3,3' $3^{\prime}, 4^{\prime}, 5,5^{\prime}$-hexahydroxy-trans-stilbene is a potent HIV-1 inhibitor. J. Med. Virol. 2015, 87, 2054-2060. [CrossRef]

33. Anggakusuma Colpitts, C.C.; Schang, L.M.; Rachmawati, H.; Frentzen, A.; Pfaender, S.; Behrendt, P.; Brown, R.J.; Bankwitz, D.; Steinmann, J.; Ott, M.; et al. Turmeric curcumin inhibits entry of all hepatitis C virus genotypes into human liver cells. Gut 2014, 63, 1137-1149. [CrossRef]

34. Wolf, M.C.; Freiberg, A.N.; Zhang, T.; Akyol-Ataman, Z.; Grock, A.; Hong, P.W.; Li, J.; Watson, N.F.; Fang, A.Q.; Aguilar, H.C.; et al. A broad-spectrum antiviral targeting entry of enveloped viruses. Proc. Natl. Acad. Sci. USA 2010, 107, 3157-3162. [CrossRef]

35. Docherty, J.J.; Fu, M.M.; Hah, J.M.; Sweet, T.J.; Faith, S.A.; Booth, T. Effect of resveratrol on herpes simplex virus vaginal infection in the mouse. Antivir. Res. 2005, 67, 155-162. [CrossRef] [PubMed]

36. Malancona, S.; Mori, M.; Fezzardi, P.; Santoriello, M.; Basta, A.; Nibbio, M.; Kovalenko, L.; Speziale, R.; Battista, M.R.; Cellucci, A.; et al. 5,6-Dihydroxypyrimidine Scaffold to Target HIV-1 Nucleocapsid Protein. ACS Med. Chem. Lett 2020, 11, 766-772. [CrossRef] [PubMed]

37. Mori, M.; Ciaco, S.; Mely, Y.; Karioti, A. Inhibitory Effect of Lithospermic Acid on the HIV-1 Nucleocapsid Protein. Molecules 2020, 25, 5434. [CrossRef] [PubMed]

38. Huth, J.R.; Mendoza, R.; Olejniczak, E.T.; Johnson, R.W.; Cothron, D.A.; Liu, Y.; Lerner, C.G.; Chen, J.; Hajduk, P.J. ALARM NMR: A rapid and robust experimental method to detect reactive false positives in biochemical screens. J. Am. Chem. Soc. 2005, 127, 217-224. [CrossRef] [PubMed]

39. Mori, M.; Kovalenko, L.; Malancona, S.; Saladini, F.; De Forni, D.; Pires, M.; Humbert, N.; Real, E.; Botzanowski, T.; Cianferani, S.; et al. Structure-Based Identification of HIV-1 Nucleocapsid Protein Inhibitors Active against Wild-Type and Drug-Resistant HIV-1 Strains. ACS Chem. Biol. 2018, 13, 253-266. [CrossRef]

40. Baeten, J.M.; Benki, S.; Chohan, V.; Lavreys, L.; McClelland, R.S.; Mandaliya, K.; Ndinya-Achola, J.O.; Jaoko, W.; Overbaugh, J. Hormonal contraceptive use, herpes simplex virus infection, and risk of HIV-1 acquisition among Kenyan women. AIDS 2007, 21, 1771-1777. [CrossRef] [PubMed]

41. Baatz, F.; Nijhuis, M.; Lemaire, M.; Riedijk, M.; Wensing, A.M.; Servais, J.Y.; van Ham, P.M.; Hoepelman, A.I.; Koopmans, P.P.; Sprenger, H.G.; et al. Impact of the HIV-1 env genetic context outside HR1-HR2 on resistance to the fusion inhibitor enfuvirtide and viral infectivity in clinical isolates. PLOS ONE 2011, 6, e21535. [CrossRef]

42. Bargellini, G.; Marini-Bettolo, G.B. Flavone, flavanone and flavonol derivatives of hydroxyhydroquinone. Gazz. Chim. Ital. 1940, 70, 170-178.

43. Hawkins, P.C.; Skillman, A.G.; Nicholls, A. Comparison of shape-matching and docking as virtual screening tools. J. Med. Chem. 2007, 50, 74-82. [CrossRef] [PubMed]

44. Hawkins, P.C.; Skillman, A.G.; Warren, G.L.; Ellingson, B.A.; Stahl, M.T. Conformer generation with OMEGA: Algorithm and validation using high quality structures from the Protein Databank and Cambridge Structural Database. J. Chem. Inf. Model 2010, 50, 572-584. [CrossRef] [PubMed] 